NBER WORKING PAPER SERIES

\title{
IMPACT OF COMPREHENSIVE SMOKING BANS ON THE HEALTH OF INFANTS AND CHILDREN
}

\author{
Kerry Anne McGeary \\ Dhaval M. Dave \\ Brandy J. Lipton \\ Timothy Roeper \\ Working Paper 23995 \\ http://www.nber.org/papers/w23995 \\ NATIONAL BUREAU OF ECONOMIC RESEARCH \\ 1050 Massachusetts Avenue \\ Cambridge, MA 02138
}

November 2017, Revised April 2019

This research is supported by a grant from the National Cancer Institute (1R21CA167578-01) to the NBER. We are grateful to Laura Argys, Ryan Brown, and Christina Robinson for valuable comments on earlier drafts of this study. The majority of Brandy Lipton's work on this project was completed while she was employed by the Agency for Healthcare Research and Quality. The views expressed in this paper are those of the authors and do not necessarily represent the views of the Robert Wood Johnson Foundation, the Agency for Healthcare Research and Quality, the Department of Health and Human Services, or the National Bureau of Economic Research.

NBER working papers are circulated for discussion and comment purposes. They have not been peer-reviewed or been subject to the review by the NBER Board of Directors that accompanies official NBER publications.

(C) 2017 by Kerry Anne McGeary, Dhaval M. Dave, Brandy J. Lipton, and Timothy Roeper. All rights reserved. Short sections of text, not to exceed two paragraphs, may be quoted without explicit permission provided that full credit, including $(\subset)$ notice, is given to the source. 
Impact of Comprehensive Smoking Bans on the Health of Infants and Children

Kerry Anne McGeary, Dhaval M. Dave, Brandy J. Lipton, and Timothy Roeper

NBER Working Paper No. 23995

November 2017, Revised April 2019

JEL No. D1,H0,I1,K0

\begin{abstract}
As evidence of the negative effects of environmental tobacco smoke (ETS) has mounted, an increasingly popular public policy response has been to impose restrictions on smoking through $100 \%$ smoke-free bans (comprehensive smoking bans). Yet sparse information exists regarding the impact these smoking bans at the state and local levels have on the health of children and infants. A rationale for expansion of smoke-free laws implicitly presumes that potential public health gains from reducing adult cigarette consumption and declines in adult ETS exposure extend to children. However, if smokers compensate by shifting their consumption of cigarettes from public venues that impose a comprehensive smoking ban to smoking at home, then these policies may have a harmful effect on children and infants. This study provides estimates of how comprehensive smoking bans impact the venue of smoking, and the health of children and infants. Using models that exploit state- and county-level changes to smoking ban legislation over time, estimates suggest that smoking bans have improved the health of both infants and children, mainly through implementation of more comprehensive bans. Further, we find no evidence of displacement among smokers (both smokers with and without children in the household), and actually find that the bans had a positive spillover effect in terms of reducing smoking inside the home - an effect which may further explain the improvement in infant and children's health. Our effect magnitudes imply that expanding comprehensive coverage from $60 \%$ (current level) to $100 \%$ of the population can prevent between approximately 1,110 - 1,750 low birthweight births among low-educated mothers, resulting in economic cost savings of about $\$ 71-\$ 111$ million annually. Health improvements among older children add to these economic benefits.
\end{abstract}

Kerry Anne McGeary

Research Evaluation and Learning

Robert Wood Johnson Foundation

PO 2316

Princeton, NJ 08543-2316

kmcgeary@rwjf.org

Dhaval M. Dave

Bentley University

Department of Economics

175 Forest Street, AAC 195

Waltham, MA 02452-4705

and IZA

and also NBER

ddave@bentley.edu
Brandy J. Lipton

San Diego State University

Graduate School of Public Health

Hardy Tower room 119

5500 Campanile Drive

San Diego, CA 92182-4162

blipton@sdsu.edu

Timothy Roeper

New York University

Department of Economics

New York University

19 West 4th Street - 6th FL

New York, NY 10012

timothy.roeper@gmail.com 


\section{Introduction}

Environmental Tobacco Smoke (ETS) exposure is not trivial. The Centers for Disease Control and Prevention (CDC) note that it threatens over 126 million non-smoking Americans, including children. An estimated 150,000 to 300,000 children younger than 18 months of age have respiratory tract infections linked to secondhand smoke, and $9 \%$ of total direct medical costs in the first year of life can be attributed to ETS exposure (Leung et al. 2003). The estimated economic burden of ETS exposure in the U.S. exceeds $\$ 5$ billion in direct medical costs and $\$ 4.7$ billion annually in lost productivity costs (Bonnie et al. 2007a).

The enormity of these economic costs justifies the continued implementation of comprehensive and extensive tobacco control programs comprising of excise tax hikes, antismoking educational campaigns, and support for smoking cessation since the 1970s. In addition, both the CDC and Institute of Medicine (IOM) strongly recommend that states and localities enact 100\% Smoke-Free Laws (comprehensive smoking bans) in all non-residential indoor locations, mainly any worksites, restaurants, and bars (USDHHS 2007; Bonnie et al. 2007b). While these recommendations aim to reduce smoking prevalence and ETS exposure for the entire U.S. population, they are based on studies that investigate the impact of smoking restrictions on smoking prevalence, smoking-related morbidities, and ETS exposure among only adults (i.e., not all ages). A key and necessary link for a comprehensive evaluation of the effectiveness of $100 \%$ SFLs has been missing from the CDC and IOM reports as very few studies have assessed whether and to what extent $100 \%$ SFLs at the state and local levels impact the health of children and infants.

The health-promoting effects of smoking bans are well documented for adults, both in terms of reducing smoking prevalence as well as non-smoking adults' ETS exposure (Stillman et al. 1990; Brauer and Mannetje 1998; Farrelly et al. 1999; Evans, et al. 1999; Valente et al. 2007). Further justification for smoking bans derives from U.S. and international research that provides evidence 
of a link from smoking bans to improvements in ETS-related morbidities for adults, such as: respiratory health, and acute myocardial infarction. ${ }^{1}$ It is important to note that these studies do not estimate the impact on infants or children. The presumption that the beneficial effects found for adults, a priori, will extend to infants and children may or may not be correct. For instance, smokers may compensate for the comprehensive restrictions by partly shifting from consuming cigarettes at banned venues to smoking at home (when children, infants, or pregnant women are present). This potential unintended displacement of smoking to the home (or other non-banned places) could raise ETS exposure of children and non-smoking family members. ${ }^{2}$

Evidence on how smoking bans impact infants and children, and whether they lead to increased smoking at home where children may be present, is very sparse. Adda and Cornaglia (2010), based on time-use data from the American Time Use Survey and the National Human Activity Pattern Survey, show that comprehensive bans in bars and restaurants decrease the amount of time that smokers spend at these locations and increase the time spent at home, though whether smokers are actually smoking more at home is not observed. ${ }^{3}$ Using a limited sample from the National Health and Nutrition Examination Survey, they also find some evidence of an increase in cotinine (a metabolite of nicotine) levels among children in smoking families, suggestive of a displacement effect. In another study, Markowitz et al. (2013) show that state-level smoking restrictions in restaurants and workplaces are not effective in improving birthweight using data from the Pregnancy Risk Assessment Monitoring System (PRAMS). More recently, Gao and Baughman

\footnotetext{
${ }^{1}$ See for instance Eisner et al. 1998, Goodman et al. 2007, Seo and Torabi 2007, Cesaroni et al. 2008, Meyers et al. 2009, Shetty et al. 2011, and Kvasnicka et al. 2018.

2 The primary site of ETS exposure for U.S. children is the home from parents or other adults smoking (Klepeis et al. 2001; Yousey 2006), and another common site of exposure is restaurants (Siegel et al. 2005). Due to their inability to choose their environment, children in general are also exposed to more ETS than non-smoking adults (USDHHS 2007). 3 “Home” was defined broadly as anyone's home, including the individual's own home or others' homes and did not differentiate between children present or not.
} 
(2017) find that comprehensive smoking bans have no positive impact on birth outcomes, and may even lead to a possible decline in the health of infants born to younger mothers.

Our study adds to this very limited evidence base, exploiting data from the U.S. Natality File and the National Health Interview Survey (NHIS) combined with detailed information on all comprehensive and limited smoking bans at local and state-levels, and provides a comprehensive analysis of how these restrictions have impacted child health. We extend the limited prior work on infants (Markowitz et al. 2013; Gao and Baughman 2017), and also provide the first national analysis of the impact of these bans on the respiratory health of older children. In addition, by exploiting information on the venue of smoking from the NHIS, we are able to directly estimate the influence of smoking bans on displacement of smoking to the home when children are present.

Our results show that localities that have enacted comprehensive smoking bans across workplaces, restaurants, and bars have experienced significant gains with respect to infant health (birthweight, low birthweight) and the health of older children (respiratory health and ETS-related morbidities). Further, we find no evidence of displacement of smoking behaviors to the home (among both smokers with and without children in the household); rather, estimates suggest that comprehensive bans have had a positive spillover effect in terms of reducing smoking inside the home - an effect which may further explain the improvement in infant and children's health. Our effect magnitudes are small though clinically important, and imply that expanding the coverage of comprehensive bans from the current level of $60 \%$ to $100 \%$ of the population can prevent between 1,110 - 1,750 low birthweight births among low-educated mothers, resulting in economic cost savings of up to $\$ 111$ million annually. Health improvements among older children add to these economic benefits.

\section{Background}

\section{A. Comprehensive Smoking Bans and Child Health Outcomes}


Very little work has directly assessed how comprehensive smoking bans have affected infants and children. ${ }^{4}$ According to a recent systematic review and meta-analysis, only five North American studies (4 from the U.S. and 1 from Canada) have examined the effects of public smoking bans on infant or child health, and none of these studies analyzes a nationally representative sample (Been at al. 2014; Faber et al. 2016). These studies generally support improvements in child health following the introduction of public smoking bans (see for instance, Rayens et al. 2008) though the risk for bias may be high due to the use of small samples that are not nationally representative and reliance on time-series or cross-sectional variation.

Two notable exceptions are Markowitz et al. (2013) and Gao and Baughman (2017), both of which investigate the impact of comprehensive smoking bans on infant health only, without explicitly examining the displacement hypothesis. In a relatively small scale study, Markowitz et al. (2013) utilize data for 29 states and New York City, based on the PRAMS and spanning 19962008, to assess how tobacco control policies affect birth outcomes. They consider the effects of state-level cigarette prices and excise taxes, and state-level comprehensive smoking bans in two venues (restaurants and workplaces), and find very limited effectiveness of these bans. Higher cigarette taxes and prices are found to elicit a stronger response, in terms of improvements in birth outcomes and particularly in averting preterm births, among teen mothers and mothers with low levels of educational attainment or on Medicaid. ${ }^{5}$ In a larger scale study, Gao and Baughman (2017) use data from the nationally representative U.S. Natality Detail File for all the births in the U.S. from 1995 to 2009 to test the impact of comprehensive smoking bans and cigarette taxes on infant birth weight, 5-minute APGAR scores and the incidence of cleft palate. Their results show, in

\footnotetext{
${ }^{4}$ Simon (2016) studied the longer-term effects of early life exposure to cigarette smoke, utilizing exogenous variation from in utero exposure to cigarette tax hikes, on the health of children between the ages of 2-17 years. He finds consistent evidence that higher cigarette taxes during pregnancy reduce prenatal smoking (based on natality data) and has longer-term positive effects on child health (based on the National Health Interview Surveys).

${ }^{5}$ Fully banning smoking in restaurants is found to improve birth outcomes among more educated and higher-income mothers.
} 
general, that smoking bans are not associated with any improvements in infant health, with some estimates pointing to adverse effects on low and very low birthweight among infants born to younger mothers.

\section{B. Comprehensive Smoking Bans and Displacement}

Few studies have considered potential displacement effects associated with smokers changing their behaviors in an effort to compensate for or circumvent the smoking restrictions. Adams and Cotti (2008) find a higher incidence of alcohol-related fatal accidents following the imposition of locally enacted comprehensive smoking bans in bars. They suggest that the benefit of a ban from smokers choosing to stay at home or reducing their smoking is partially offset by the increased miles driven by smokers wishing to smoke and drink, netting an increase in alcoholrelated accidents. Adda and Cornaglia (2010) find that comprehensive smoking bans in restaurants and bars reduce the amount of time that smokers spend at these locations (during both weekdays and weekends) and increase the time spent at home (on weekdays though not on weekends); ${ }^{6}$ they also find some increase in cotinine levels among children in smoking families, though these effects are imprecise and not always consistent, and infer from these estimates that smokers may be shifting their smoking to inside their home.

Our study expands upon this limited literature in several ways. First, by including the earliest years of legislation, as well as state and local bans, we are able to exploit greater variation in policy and at a finer level than Markowitz et al. (2013), Gao and Baughman (2017) and Adda and Cornaglia (2010). Second, our study uses the most comprehensive and nationally representative data on birth outcomes, child health and tobacco policy to provide a more complete picture of the impact of smoking bans on infants and children. The national data raises the external validity of our

\footnotetext{
${ }^{6}$ The time-use measures do not capture the act of smoking, either actual smoking or reported smoking. Hence, increased time at home may not necessarily mean that the smokers were consuming cigarettes during their expanded time spent at home, or consuming cigarettes in homes with children, as these analyses did not differentiate households with and without children.
} 
estimates, and the expanded sample sizes in the NHIS and the natality data are important for maximizing statistical power in order to reliably detect effect magnitudes which may be potentially small. To the best of our knowledge, we also provide the first national study of the effects of comprehensive bans on ETS-related morbidities among older children. Third, we clarify if the impact of the smoking bans on infant health is due to "own effects", that is a reduction in smoking by a pregnant woman exposed to these restrictions, or due to external effects, that is a reduction in a non-smoking mother's exposure to ETS because others around her are smoking less. Finally, we provide the first direct estimates in the literature informing the displacement hypothesis by assessing whether comprehensive smoking bans increase the probability that a smoker will now smoke at home with children present.

\section{Data}

We use two restricted datasets with geographic identifiers to investigate the effects of both local and state comprehensive smoking bans on the health of children and infants and on the likelihood of smoking at home. Each dataset offers unique advantages, is nationally representative, and has a large sample size, allowing us to maximize statistical power and assess differential effects across socio-demographic factors.

\section{U.S. Vital Statistics Natality Data}

In order to assess the effects of comprehensive smoking bans on birth outcomes we utilize data on individual birth records from the U.S Vital Statistics Natality Detail Files. Detailed information on all individual births occurring in the 50 states and D.C. are submitted by hospitals to state vital registration offices, which is then reported to the National Center for Health Statistics (NCHS). Information on each birth includes date and place of birth, along with the demographic characteristics of the mother and father such as age, race, education, marital status, whether born in the U.S., and parity. In order to minimize measurement error, we utilize exact information on the 
timing of enactment and match the policy data based on maternal county of residence and the start of pregnancy (month and year). The start of pregnancy is imputed based on gestational age and birth month. ${ }^{7}$

We utilize data from 1990 through 2012, representing 86.3 million U.S. births. This period enveloped the first comprehensive smoking bans in three municipalities in CA to the proliferation of these bans over the next two decades when almost 900 municipalities enacted a comprehensive smoking ban in at least one venue and almost two-thirds of the U.S. population were exposed. We measure two categories of infant health: 1) birthweight; and 2) gestation. Birthweight is measured as a continuous outcome and alternately as an indicator for low birthweight (weighing less than 2,500 grams). Gestational age is measured continuously in weeks, and also as an indicator for whether the infant was born preterm (gestation $<37$ weeks).

Self-reported information on maternal smoking during pregnancy is also available. ${ }^{8}$ Birth certificates are generally thought to provide a reasonably reliable source of data on prenatal smoking status for large observational studies (Nielsen et al. 2014), although underreporting of smoking status has been suggested for as much as $20-30 \%$ of smokers (Tong et al. 2013; Brachet 2013). ${ }^{9}$ Our main specifications are based on reduced form intention-to-treat analyses, and thus do not require any information on maternal information. We use information on maternal smoking only in supplementary models to provide some indirect information on the channels underlying the effects of the smoking bans on birth outcomes. In doing so, we note the limitation imposed by the potential underreporting of smoking status.

\footnotetext{
${ }^{7}$ Results are not sensitive to using a standard 40-week gestational period.

8 These outcomes are not reported by some states (for instance, CA, IN, NY, SD, OK) over all or part of our sample period. We exclude births occurring in these states when analyzing these behaviors. Limiting all analyses to those states with consistent information on smoking does not materially alter our results or conclusions.

${ }^{9}$ Brachet (2013) provides an excellent discussion of how misclassification of maternal smoking in the natality files may bias the policy effects of cigarette taxes and consequently the instrumental variables estimate of the effects of maternal smoking on birthweight.
} 


\section{National Health Interview Surveys (NHIS)}

The National Center for Health Statistics (NCHS) has used the NHIS to monitor the nation’s health since 1957. In order to assess the effects of smoking bans on child health and on the venue of smoking, we utilize information from the NHIS after the sampling plan redesign in 1997, spanning 1998-2013. Because we use the one year lag of the smoking ban policies in this analysis, these data cover policy years 1997-2012. This results in a pooled sample of 167,328 children under the age of 18. The primary child health outcomes of interest, obtained via parental reports in the child health files, measure adverse health conditions linked to or which may be exacerbated by ETS: asthma (ever diagnosed; asthma attack in the past year; hospital emergency room visit related to asthma), hay fever (past year), any respiratory allergies (past year), three or more ear infections (past year), whether the child had an emergency room (ER) visit for any reason in the past year, and selfreported general health status.

The NHIS also includes a proxy measure for ETS inside the home in the 1998 Health Promotion Supplements and the 2000, 2005, and 2010 Cancer Supplements, yielding 41,096 adults with at least one child under age 18 residing in the home. The ETS exposure data are derived from questions regarding smoking anywhere inside the home.

All NHIS waves include information on maternal and paternal demographic characteristics such as age, race, education, marital status, whether born in the U.S., income and the smoking status of the parents and other adult household members. The restricted NHIS data were accessed through the Census Research Data Center.

\section{Tobacco Policy}

To capture information on smoking bans over time, we use the most complete dataset detailing information on comprehensive smoking bans passed and implemented at the local (city and county-level) and state levels compiled by American Nonsmokers’ Rights Foundation (ANRF). 
For clarity, ANRF prefers the term 100\% smoke-free laws (SFLs), though for consistency we continue to use the term, comprehensive smoking bans. Comprehensive smoking bans are much more exclusionary and complete compared to the popular clean indoor air acts (limited smoking bans) of the 1980s and 1990s, which also excluded venues including worksites, restaurants and free standing bars (USDHHS 2006; USDHHS 2007; Bonnie, et al, 2007a, Bonnie et al. 2007b). In general, comprehensive smoking bans mandate that all areas in these venues must be completely smoke-free, with minor exceptions. Limited bans, in contrast, either exempt areas or groups, permit smoking in enclosed, separately ventilated smoking rooms, or allow for other exemptions.

The ANRF data offer complete information on the coverage of the comprehensive smoking bans in workplaces, restaurants, and bars, and the implementation date that the provisions became fully effective. To measure ban exposure, we create a set of dichotomous indicators by locality and year to document whether a given county in a given year had implemented a smoking ban in each venue, and whether each ban is comprehensive or limited in scope. See Table 1 for more description of sample coverage.

In our empirical models, in order to bypass collinearity across the enactment and implementation of these separate bans and to capture the smoking restrictions in their strongest capacity, we further construct a consolidated indicator for comprehensive smoking bans in all venues, which captures localities that have enacted comprehensive bans across all three sites - workplaces, restaurants, and bars. Though the modal locality introduces the bans in all three venues at the same time, it is more common for localities to have restaurant and bar coverage before having workplace coverage than the reverse; hence, this consolidated indicator, which would not turn on until all venues in the locality have banned smoking, may pick up some cumulative effect from changing cultural norms regarding smoking as these bans become more pervasive. In order to disentangle this timing further and assess robustness to alternate definitions, we also test an indicator for 'any comprehensive 
smoking ban', which signifies if the locality has enacted a comprehensive smoking ban in any of the three venues.

Our use of these data (1990 - 2012) add value to the literature, as prior studies primarily use information on clean indoor air legislation or comprehensive smoking bans at the state level only; our analyses utilize all currently available information at both the state and local (county and city) levels in order to minimize measurement bias and fully capture an individual's potential exposure to comprehensive smoking bans in their vicinity, over the longest period of time used to date. ${ }^{10}$ There were a total of 4,984 ban changes across venues and ban types, and specifically 1,273 counties experienced the strictest ban (comprehensive bans in all venues). Decomposing this policy variation, 24 states implemented comprehensive bans in all venues covering a total of 1,193 counties that did not previously have bans, while 80 counties implemented comprehensive bans at the local (county or city) level. Statewide bans accounted for 80.5 percent of treated births, and county bans accounted for the remaining 19.5 percent.

Information on state-level taxes for cigarettes is obtained from The Tax Burden on Tobacco: Historical Compilation (Orzechowski and Walker 2012). We match information on the comprehensive and limited smoking bans and cigarette excise taxes to the birth records based on maternal county of residence and the start of pregnancy (month and year). We match the policy information based on start of pregnancy, rather than date of delivery, since infant health is affected by in utero exposure to ETS over the course of the pregnancy. Furthermore, evidence suggests that prenatal smoking is most responsive during the first trimester (Colman, Grossman, and Joyce 2003; Colman and Joyce 2003). For the records in the NHIS, we match the comprehensive and limited smoking bans and cigarette excise taxes based on county of residence and the one year prior to the

\footnotetext{
${ }^{10}$ Pesko et al. (2016) show that incorporating local policy variation, in their case sub-state variation in the cigarette price vs. more aggregated state-level cigarettes prices and taxes, can lead to significant differences in the estimates of the policy response.
} 
interview date, which allows for a one-year exposure lag mirroring the 9-month exposure lag (over the pregnancy period) utilized in the birth certificate data. Since we would expect comprehensive smoking bans to affect adult smoking behavior first and child health second, we do not incorporate a lag when examining the adult outcome (i.e., whether anyone smokes inside the home).

Table 1 presents means for our analysis samples of interest, births to mothers with a highschool degree or less and births to unmarried mothers with a high school degree or less, relative to all births. These means are derived from the Vital Statistics Natality files, and Table 2 presents outcome means for the samples based on the NHIS. Table 1 shows the percent of the samples exposed to comprehensive smoking bans by venue (comprehensive), limited smoking bans (limited) and no bans over the sample period from 1990-2012. Over our sample period, nearly 20\% of all births were in localities with comprehensive coverage in at least one venue and nearly $11 \%$ of all births were covered by comprehensive smoking bans in all three venues. In 1995, less than $2 \%$ of the population resided in a locality or state with a comprehensive smoking ban in each of the three venues. By 2012, over 48\% of the population was exposed to a comprehensive worksite ban, over $64 \%$ were exposed to full bans in restaurants, and over $60 \%$ were exposed to these restrictions in freestanding bars.

\section{Methodology}

Our empirical analysis is based on specifications that directly link the comprehensive bans to infant and child health outcomes. The research design is a difference-in-differences (DD) approach focusing on the reduced-form effect of being exposed to a locality with comprehensive smoking bans in workplaces, restaurants, and bars. For each measure of infant and child health, we estimate the following baseline health production function:

$$
\mathrm{H}_{\mathrm{icst}}=\alpha_{\mathrm{cs}}+\theta_{\mathrm{t}}+\mathrm{BAN}_{\mathrm{cst}-1} \beta+\mathrm{X}_{\mathrm{icst}} \lambda+\mathrm{Tax}_{\mathrm{st}-1} \delta+v_{\mathrm{icst}}
$$


In equation (1), H denotes a specific measure of infant or child health (e.g. birthweight, gestation, respiratory ailments) for a given birth $i$ occurring in county $c$ in state $s$ and year $t$ (in the birth records) or for a given child $i$ residing in county $c$ in state $s$ and interviewed in year $t$ (in the NHIS). BAN denotes the vector of smoking bans, including types of bans, effective in the county (of birth, in the birth records; of residence in the NHIS) during pregnancy (for the birth records) or during the year prior to interview date (in the NHIS). The vector X represents individual characteristics. In models for birth outcomes, $\mathrm{X}$ includes maternal characteristics such as age, educational attainment, marital status, and race/ethnicity. In models for child health, based on the NHIS, X includes child characteristics (age, gender, race/ethnicity and birth weight) and maternal characteristics (age, educational attainment, and marital status). All models also control for the cigarette excise tax, which previous studies have found to affect maternal smoking and infant health (Colman, Grossman, and Joyce 2003; Colman and Joyce 2003; Evans and Ringel 1999). ${ }^{11}$ Equation (1) further includes year $\left(\theta_{t}\right)$ and area fixed effects $\left(\alpha_{\mathrm{cs}}\right)$ at the county level in our preferred models (and alternately at the state level, for comparison), which respectively control for any national trends, county-specific time-invariant unobservable influences such as tobacco sentiment, strength of the tobacco economy in the state (for instance, tobacco growing states), and other fixed area-level factors such as culture and geography. Standard errors are clustered at the state level and account for any correlation of the errors within state cells and over time. ${ }^{12}$

The parameter of interest is $\beta$, which captures the net reduced-form effect of the types of smoking bans on infant and child health, operating through any reinforcing and/or counteracting

\footnotetext{
${ }^{11}$ Estimates are robust to excluding cigarette excise taxes from the specification. In models with the cigarette tax as the outcome measure, the coefficient of the comprehensive smoking ban is statistically and economically insignificant. Thus, we do not find any indication that the timing of the bans predicts or is systematically correlated with within-state changes in the cigarette excise tax.

${ }^{12}$ We estimate all models using ordinary least square. Results are robust to estimation via logit or probit regression for dichotomous outcomes.
} 
mechanisms. This effect is identified off the variation in the enactment of smoking bans within counties over time.

We extend these specifications further to address specific issues. With respect to infants, prenatal in-utero exposure may result from maternal smoking as well as maternal ETS exposure from cigarette consumption of other family members or individuals even if the pregnant woman herself does not smoke. Thus, we also estimate equation (1) alternately controlling for maternal smoking. Comparison of the effect magnitudes between these specifications (excluding and controlling for maternal smoking) can inform on whether, and to what extent, any potential effects on infant health are being driven by the mother's own smoking or by maternal exposure to ETS.

Low birthweight can result from preterm birth or intra-uterine growth restriction (IUGR). Smoking is the leading cause of IUGR, and fetal growth is also affected by prenatal ETS exposure (Windham et al. 2000). The causes of preterm birth are not as well understood (Institute of Medicine 2007), though smoking and ETS exposure are potential risk factors (Windham et al. 2000). In order to separate these effects, we also define a measure of fetal growth, which is birthweight adjusted for gestational age.

We focus the main analyses to children and infants born to low-educated mothers, with at most a high-school degree. These infants and children are a particularly vulnerable group given that lower-educated mothers are significantly more likely to smoke during pregnancy (18.8\% prevalence rate relative to mothers with some college or higher educational attainment, who have a prevalence rate of $6 \%$ ), and are also more likely to live in neighborhoods with a higher smoking prevalence in general, thus exposing themselves and their children to ETS. Results for the full sample are reported in the appendix tables, and generally show similar patterns though expectedly smaller effect magnitudes as the bans impact higher-educated mothers to a much lesser degree. 
Next, we estimate versions of the above specifications directly linking the comprehensive ban to the venue of smoking among adult smokers, based on information from the restricted NHIS. Specifically, we assess the displacement hypothesis and test whether adults exposed to these comprehensive smoking bans in workplaces, restaurants, or bars are more likely to smoke at home with children present.

Finally, we conduct a series of checks to assess: 1) timing of the effects and differential prepolicy trends; 2) robustness to alternate measures and controls for the smoking bans; 3) heterogeneity in the policy effects across urban / rural counties; 4) heterogeneity in the policy effect across mother's marital status and the child's age (in models of child health based on the NHIS); 5) potential mediating effects of the bans through prenatal alcohol use; and 6) robustness to combining health outcomes in the NHIS within a broader health "index" in order to minimize type I error from multiple testing. ${ }^{13}$

\section{Results}

\section{V.A. Birth Outcomes}

Table 3 presents estimates of equation (1) for infant health outcomes based on the birth records. These models consider the strictest combination of smoking bans, assessing how birth outcomes differ in localities that have enacted comprehensive bans in all three venues - worksites, restaurants, and freestanding bars - relative to two separate control localities. Panels A and B in the tables represent the differences in these reference groups. In Panel A, the reference group comprises all other localities that do not have a comprehensive ban in all venues, whether or not they enact any smoking ban. In Panel B, the reference group comprises localities that have no ban of any kind; localities with limited and non-comprehensive bans across all venues are excluded

\footnotetext{
${ }^{13}$ We thank the anonymous reviewers for suggesting some of these checks.
} 
from these analyses. This comparison underscores the potential maximal effect by contrasting the two extremes in terms of comprehensive bans in all three venues versus no bans in any venue. ${ }^{14}$

We report models alternately controlling for state vs. county fixed effects for comparison, since, as noted earlier, most of the policy variation (80.5\%) in comprehensive bans is driven by statewide changes. In discussing the estimates, however, we focus on models with county fixed effects as these rely only on within-county variation in the implementation of bans for identification. In contrast, identifying variation in models with state fixed effects utilizes both within-state variation in the bans over time (due to statewide policy changes, for instance) as well as any sub-state cross-county variation in bans (due to local policy changes). Model (1) in Panel B suggests that comprehensive bans in all venues are associated with a 13 gram increase in mean birthweight, which translates to about a $0.4 \%$ increase relative to the sample mean. The effect magnitude, with only the state fixed effects, is somewhat larger, suggesting an 18 gram increase. The smoking restrictions are also associated with a $0.24-0.3$ percentage point decline in the likelihood of low birthweight (3-4\% decrease relative to the sample mean), though this estimate is not statistically significant at conventional levels in the model with county fixed effects. The potentially larger response for low birthweight is consistent with prior studies that also find larger impacts of income-support policies and other transfer programs at the lower tail of the birthweight distribution (Wehby, Dave, and Kaestner 2016; Hoynes, Miller, and Simon 2015; Almond, Hoynes, and Schanzenbach 2011). This estimated response captures the effect of a locality with no ban in any venue imposing a comprehensive ban in all venues. This extreme comparison increases the standard errors as localities with limited bans are not part of analysis.

Furthermore, in order to assess whether there is heterogeneity in the policy response if the policy is driven by a statewide enactment of the ban vs. a local change, we also estimated models

\footnotetext{
${ }^{14}$ We also estimate more disaggregated specifications, which separately control for the other bans (discussed later under "Specification Checks").
} 
with state fixed effects that rely only on the statewide variation in comprehensive bans. ${ }^{15}$ These models yield very similar effect magnitudes, suggesting an improvement in birthweight by 15 grams and a reduction in low birthweight by 0.21 percentage point. Furthermore, when we separately control for comprehensive bans originating at the local level in the same models, the effect magnitudes for both state-driven and local-driven policy changes are very similar, and these estimates are contained within the confidence intervals of the estimates in Panel B of Table 3 for all outcomes.

The increase in birthweight (and reduction in low birthweight) may reflect either an improvement in fetal growth and/or an increase in gestational age (reduction in preterm birth). We consider gestational age and preterm birth in models (3) and (4). Essentially, we find a significant increase in gestational age by about 0.09 weeks ( $0.2 \%$; model 3$)$, though this increase does not seem to operate at the lower tail of the gestation distribution and we find no significant effects on the likelihood of a preterm birth (coefficient magnitude corresponds to about a $\%$ decline). Model (5) informs whether the comprehensive smoking bans have an impact on birthweight conditional on gestational age by presenting estimates for fetal growth, defined as birthweight in grams relative to gestational age in weeks. We find an increase in fetal growth by about 0.2 gram (or $0.2 \%$ ), though the effect is insignificant when including county fixed effects.

Health-promoting effects of comprehensive smoking bans on birth outcomes capture two potential channels. The first channel represents improvements in infant health from reduced exposure to secondhand smoke by pregnant women, as others around her are incentivized to reduce their smoking behaviors due to the bans. In contrast to this external effect, improvements in infant health may also be realized from a direct reduction in prenatal smoking. In models (6)-(10), we control for prenatal smoking in order to isolate the external effects of smoking restrictions on infant

${ }^{15}$ Estimates are not reported and available upon request from the authors. 
health through reduced exposure to environmental tobacco smoke (ETS). Including prenatal smoking in the specification is potentially problematic because the mediator is itself endogenous, and hence would lead to biased estimates (Angrist \& Pischke 2009). ${ }^{16}$ Furthermore, as many as 2030\% of smokers may misreport (Tong et al. 2013; Brachet 2013), which can lead to an attenuation of the estimated effect of prenatal smoking on infant health. These caveats notwithstanding, the magnitudes expectedly decline somewhat when we control for maternal smoking, suggesting that at least part of the improvements in infant health are driven by a reduction in prenatal smoking. Specifically, comparing models (1) - (5) to models (6)-(10), approximately $15-20 \%$ of the effect on birth outcomes is due to a reduction in prenatal smoking (an "own-effect" from the mother reducing her own smoking due to the smoking restrictions), and the remaining $80-85 \%$ of the effect may be due to potential reductions in ETS. ${ }^{17}$

We also estimate models for samples restricted to mothers who do not smoke, and find similar effects which is validating. Furthermore, in models which treat prenatal smoking as an outcome, we find that comprehensive bans in all venues reduce the probability of prenatal smoking by about 0.008 (0.8 percentage point). Prior work (Evans and Ringel 1999; Wehby et al. 2013) suggests that prenatal smoking reduces birthweight by about 200-400 grams. In our specification (model 6 in Table 3 Panel B), the coefficient of prenatal smoking is -214 (p-value $=0.000$ ) also suggesting about a 200 gram decrease in birthweight associated with prenatal smoking. Combining these two estimates $[-0.008 *-214=1.7]$ suggests that the mean increase in birthweight in the population, from the channel that operates from cumulative smoking bans to reduced prenatal

\footnotetext{
${ }^{16}$ As an alternative, we also directly estimated the effect of the comprehensive bans on the joint probability between low birthweight and prenatal smoking using multinomial logit models (MNL). The marginal changes in these joint probabilities allow us to pick up potential interactions between infant health and prenatal smoking, and assess both unconditional and conditional (on prenatal smoking) effects of the comprehensive SFLs on infant health. Results from these analyses also suggested that about $20 \%$ of the observed effect of smoking bans on low birthweight represents an "own-effect" operating through a reduced probability of the mother smoking during pregnancy.

${ }^{17}$ This decomposition is back-of-the-envelope and should be interpreted with caution.
} 
smoking, would be 1.7 grams. Model 1 in Table 3 Panel B suggests a mean increase in birthweight of about 12 grams. Thus, at least about $14 \%$ of this total effect is due to a reduction in prenatal smoking, and the rest is due to potential decrease in ETS exposure by pregnant women and their unborn children. ${ }^{18}$

Models in Table 3 further indicate that higher state excise taxes on cigarettes are consistently and significantly associated with an improvement in infant health (higher birthweight, reduced likelihood of low birthweight, longer gestation, and higher fetal growth). We find elasticity estimates of birthweight and low birthweight with respect to cigarette taxes that are consistent with the literature (Evans and Ringel 1999). ${ }^{19}$

The specifications in Panel A in Table 3 assess the effects of a combined comprehensive ban on smoking in all three venues (worksites, restaurants, and bars), though this time the reference group includes all other localities. Thus, the reference group is a mixture of all localities that may impose no bans at all, or comprehensive bans in just a few venues (but not all three), or those which impose limited bans. Since the reference group includes localities which also have smoking restrictions, though albeit not comprehensive smoking bans in all three venues combined, the effect magnitudes are expectedly smaller. Nevertheless, these estimates continue to suggest that cumulative smoking bans in all three venues combined are associated with improvements in infant health, and much of the effect appears realized through potential decreases in second-hand smoke exposure, comparing models (1)-(5) with models (6)-(10).

\footnotetext{
${ }^{18}$ We further assess heterogeneity in the infant health effects among low-educated mothers by marital status. These models suggest improvements in infant health born to both married and unmarried mothers, though with results consistently indicating larger and significant effects among low-educated married mothers. This may reflect complementarity in smoking between both spouses, and reduced exposure to ETS in the home if the husband's smoking is moderated because of the smoking restrictions. Taxes on the other hand have a much larger effect for low-educated unmarried mothers, which may reflect this group's relatively lower income levels. Studies have shown that smoking rates among lower income individuals are generally more responsive to cigarette excise taxes (Colman and Remler 2008).

${ }^{19}$ Estimates from models (1) and (2) in Table 3 imply a tax elasticity of 0.0014 for birthweight and 0.022 for low birthweight.
} 
The estimates discussed in Tables 3 represent an average effect realized over all births born to mothers with lower educational attainment. It should also be noted that all of these estimates presented and discussed above are still “intention-to-treat” (ITT)-type average population effects. That is, these effects are averaged over two groups - those impacted by the smoking bans and those not impacted. Conditioning on prenatal smoking, the improvement in infant health is most likely operating through a reduction in ETS exposure as adults around the pregnant woman and in her locality of residence cut down on their smoking. These bans should not have any major first-order effects on non-smoking mothers who are not exposed to ETS. Data from the NHANES (1999-2000 and 2001-2002), based on serum cotinine levels as a biomarker of exposure, indicate that about 43$51 \%$ of non-smokers are exposed to secondhand tobacco smoke (USDHHS 2006). This is the population - those who are being exposed to ETS - that would presumably experience the largest benefits from being covered by a comprehensive ban in all venues. We can use this prevalence of the population exposed to ETS (about 50\%) to roughly inflate the ITT estimates by a factor of two and derive a ballpark treatment-on-the-treated effect. That is, among the population that is exposed to ETS, comprehensive bans in all three venues are associated with $0.6 \%$ increase in mean birthweight and about a 5\% reduction in the likelihood of a low birthweight infant.

\section{B. Child Health Outcomes}

As described above, we find that comprehensive smoking bans are effective in improving infant birth outcomes, among low-educated mothers. We extend these analyses to older children using data from the NHIS; these results are reported in Table 6-8. These results expand the literature by providing the first national estimates of the impact of comprehensive smoking bans on child health outcomes, and a direct test of whether the bans are impacting the likelihood of a smoker consuming cigarettes inside the home with children present. 
For consistency and in order to focus on vulnerable groups, we continue to present and discuss results for children with low-educated mothers. The child health outcomes considered are health conditions which have been linked to exposure to ETS. The smaller sample size of the NHIS, compared to the Natality Files, reduces the precision of these estimates, and so they should be interpreted as suggestive. This limitation notwithstanding, there is indication that comprehensive smoking bans are also effective in reducing adverse respiratory health conditions among children in low-educated households.

Table 6 reports estimates for the combined effect of having comprehensive smoking bans in worksites, restaurants and bars, with state and county fixed effects. For each respiratory outcome, we present models for two samples: 1) children of lower educated mothers; 2) children of lower educated mothers who have been diagnosed with asthma. The second sample allows us to investigate whether smoking restrictions affect respiratory events among a group of children who would be especially vulnerable to adverse health effects due to ETS. Each row represents a separate specification by health outcome. Estimates for the full sample suggest a similar pattern of estimates, albeit expectedly with smaller magnitudes. These results and those for additional samples are reported in the appendix.

In general, we find that comprehensive smoking bans are associated with a reduction in respiratory allergies, asthma attacks, ER visits, three or more ear infections and reports of fair or poor health. These effects are statistically significant and the size of the effect varies, as expected with the level of vulnerability of the children. For example, among children living with a lower educated mother, there is evidence that comprehensive smoking restrictions in all venues leads to substantial declines in adverse respiratory conditions and any ER visit in the past year. The latter effect is especially sizeable at about 5 percentage points (over a 25\% decrease). The effects are 
magnified among children of lower educated mothers and who have been diagnosed with asthma, though with the inclusion of county fixed effects we do lose precision with the smaller samples.

It should be noted that while children may not be necessarily exposed to ETS directly from worksites, comprehensive smoking bans in workplaces may induce adults to quit smoking or smoke less, thus reducing children's exposure to ETS overall. Smoking restrictions in bars would also be expected to exert their effect in a similar manner, whereas restrictions in restaurants may reduce children's direct exposure to ETS while in restaurants as well as reduce their exposure overall in all places if adults are smoking less in general, which is consistent with prior work (Carton et al. 2016; Anger et al., 2011; Shetty et al. 2011; Fichtenberg et al. 2002; Eisner et al., 1998).

The estimates discussed thus far indicate that, on the net, comprehensive smoke-free laws have the capacity to improve both infant and child health. However, it is not clear whether these improvements are being moderated by any counteracting effect due to adults shifting their smoking to inside their home as a result of comprehensive restrictions imposed on their smoking behaviors in other places, workplaces, restaurant and bars. That is, if the smoking restrictions are displacing at least some of the smoking from the banned places to inside the home, where children or expectant mothers may be present, then observed improvements in infant and child health may be smaller than would otherwise be possible. Table 8 directly assesses potential displacement by estimating models for whether adults (in lower-educated households with children) are more or less likely to smoke inside the home (on one or more days per week) as a result of the comprehensive smoking bans. Conditional on living with children who are younger than 18 years of age, we consider 3 groups: 1) the entire subsample as defined, 2) those among the subsample that are also current smokers; 3) those in the subsample that are current or former smokers.

Table 8 is presented in two panels. Panel A provides results for a reference group of all localities without comprehensive smoking bans in all three venues, which could include those with 
limited smoking bans. Coefficient estimates in Panel A are generally negative and in many instances, economically meaningful, but not statistically significant given the dilution of the reference group.

Turning to the results in Panel B, these are expectedly larger in magnitude and generally significant. The reference group here is all localities with no ban of any type, offering the strongest “treatment” as a locality with no ban switches to a comprehensive ban in all venues. Specifically, in models (1) and (4) we find negative but insignificant effects. However, this group includes never and former smoking adults, who should be minimally impacted by these bans. ${ }^{20}$ Next, consider the group that should most likely be affected by the bans in terms of their venue of smoking - current smokers - in models (2) and (5). We find consistent evidence that comprehensive smoking restrictions in all venues are associated with a reduction in smoking inside the home where children are present. About $60 \%$ of smokers in the NHIS have smoked inside the home on at least one day in the past week. In fact, the estimates presented Table 8 Panel B suggest a sizeable decline of 1122 percentage points in the prevalence of smoking inside the home, or about an $18-36 \%$ decrease relative to the mean prevalence. We also expand the sample to include both current and former smokers (models 3 and 6), as it is possible that smoking bans may affect the duration of smoking abstinence and relapse among former smokers. The model with county fixed effects suggests a smaller though significant 6 percentage points decline (10\% relative to the mean) in the likelihood of smoking at home. Therefore, not surprisingly we find that the largest effects are expectedly realized among current smokers. ${ }^{21}$ Given the lack of evidence of displacement, our results suggest a positive transmission channel whereby the smoking bans may be further reducing children and pregnant women’s exposure to ETS by reducing other adult members’ smoking inside the home.

\footnotetext{
20 The NHIS question specifically asks “Does ANYONE smoke inside the home?" and is asked of only the sample adults. Never smokers may be impacted if they are living with a former or current smoker.

${ }^{21}$ When we stratify our analyses among low-educated mothers across marital status, we find generally similar sized negative effects on smoking at home across both groups.
} 
Adda and Cornaglia (2010) found that bans in restaurants and bars reduce the time that smokers spend in these venues and increase their time spent at home; our results suggest that this increase in time spent at home does not translate into additional smoking inside the home where children present. $^{22}$

This reduction in smoking inside the home likely reflects a reduction in the overall addictive smoking stock. There is evidence that comprehensive smoking restrictions are associated with reduced smoking participation and a higher likelihood of smoking cessation (USDHHS 2006; USDHHS 2007; Bonnie et al. 2007a; Bonnie et al. 2007b; Anger et al. 2011; Carton et al. 2016). Thus, if adults are less likely to smoke in general, and if current smokers are smoking less (and less frequently), this would lead to reduced addictive smoking stock and a reduced urge to smoke when at home. Relatedly, as smoking bans reduced smoking participation and consumption, this "blanket” decline also extends to a decline in smoking at home.

Our findings of negative effects of a higher cigarette excise tax on smoking inside the home is consistent with this hypothesis. Higher cigarette taxes should not have any first-order effects on the venue of smoking since they do not change the relative cost of smoking at home versus outside. Hence, as higher cigarette taxes reduce smoking in general, this decline - as with the comprehensive smoking bans - also extends to a decline in smoking at home.

\section{Specification Checks}

To account for additional considerations, we implement various specification checks. First, we test two alternate definitions of smoking bans: a) any comprehensive ban in place (i.e, in workplaces, restaurants, or bars) and b) any ban in place, limited or comprehensive. These alternative definitions may better account for initial effects in states and localities with early bans in at least one venue and a potentially long lag between initial implementation and having

\footnotetext{
22 This does not preclude children being exposed to ETS elsewhere, but on the net our estimates suggest that comprehensive smoking bans have had significant beneficial health effects for children.
} 
comprehensive bans in all three venues. Smoke-free indoor locations may become the norm in such areas even before formal implementation, which may cause us to underestimate the effects of indoor smoking ban policies in our main models. On the other hand, informal or limited bans may also be less of a deterrent and therefore weaker than formal comprehensive bans. Table 5 presents estimates of the effects of "any comprehensive ban - in at least one venue” on infant health, and Table 7 presents corresponding estimates for older children's health. These results for a comprehensive ban in any venue are qualitatively similar to the results for a combined comprehensive ban in all venues and continue to indicate improvements in child health. The effect magnitudes are generally smaller when compared with the effect of a comprehensive ban in all venues. When we consider a broader definition, which captures any comprehensive or limited ban in any venue, the effects are smaller and statistically insignificant, and in the county fixed effects models, these effects of any comprehensive or limited ban become essentially zero. ${ }^{23}$

We find these results reassuring in that they are consistent with a "dose-response” relationship. Stronger, more encompassing coverage is associated with larger effects. The strongest health effects emerge when a locality with no bans switches to comprehensive bans in all venues (Tables 3 and 6, Panel B); effects are still significant but slightly smaller when an average locality with no comprehensive bans (this could include a locality with limited bans or no bans at all) switches to comprehensive bans in all venues (Tables 3 and 6, Panel A); effects are generally significant but again weaker if an average locality with no comprehensive bans (this could include a locality with limited bans or no bans at all) switches to a comprehensive ban in at least one venue (Tables 5 and 7); and finally, effects are insignificant and close to zero if an average locality with no bans institutes some ban (either limited or comprehensive in at least one venue), capturing the “weakest” form of coverage across these specifications.

\footnotetext{
${ }^{23}$ Results are available upon request.
} 
We also separately estimated effects of comprehensive workplace bans and comprehensive bans in bars and restaurants. While the patterns suggest that both are associated with improvements in infant health, the effects tend to be stronger and more significant with respect to the workplace bans. For instance, with respect to the reduction in low birthweight associated with a comprehensive ban in all three venues, about two-thirds of this reduction is coming from a comprehensive workplace ban, and about a third is due to a comprehensive ban in bars and restaurants. The stronger effects for workplace restrictions may be due to two reasons: 1) these are more salient as a mechanism for infants and children, as adults who are exposed to these restrictions may be more likely to reduce their smoking; 2) it is more common for localities to have restaurant and bar coverage before having workplace coverage, and thus we may pick up a cumulative effect from changing cultural norms regarding smoking as these bans become more pervasive.

Some studies in the literature (for instance, Adda and Cornaglia 2006) utilize a population coverage measure to capture exposure to the smoking restrictions. In alternate models, we tested a continuous measure of the percent of the state population that is covered by comprehensive bans in all venues. Estimates from these models are in line with the effects of the comprehensive ban indicator, discussed above. Based on the coverage measure, we find that moving from 0 to $100 \%$ coverage would improve birthweight by 13 grams, reduce low birthweight by 0.2 percentage point, raise gestation by 0.07 week, and increase fetal growth by 0.22 gram (estimates which are very similar to those reported in Table 3 Panel B).

Given that it may take time for smoking norms to change and it may also require multiple attempts for smokers to quit successfully when exposed to bans (or it may take some cumulative exposure period to the bans before smokers are incentivized to change their behaviors), there is a strong potential for smoking bans to have an impact on infant health with some lag and for the effects to possibly compound over time. To further disentangle some of these effects and their 
timing, we estimate an event study specification and present the results in Table 4 and in Figures 1A - 1D. Disentangling the timing reduces precision. However, the results are validating and underscore three points. First, estimates are robust to whether the analyses are restricted to evertreated counties (Table 4 Panel A and Figures 1A, 1B) or all counties (Table 4 Panel B and Figures 1C, 1D), addressing the concern that trends in counties which never institute a comprehensive ban over the sample period may be systematically different and thus not a valid counterfactual. ${ }^{24}$ Second, there are no lead or "placebo" effects of the comprehensive smoking bans on infant birth outcomes; positive health effects of the comprehensive smoking bans in all venues materialize only after the mother has been exposed to the bans, not before. Finally, we do find some evidence of a lag in the policy response. Interestingly, the lagged effects are generally stronger and are consistent with a) smoking behaviors responding to the bans with a lag; and/or b) infants responding to both in utero exposure as well as an improvement in maternal health endowment due to maternal exposure to the bans prior to pregnancy.

To explore whether smoking bans have a larger effect in areas where smoking is more prevalent, we stratified our analyses of infant health and children's health by urban/rural status (Appendix). ${ }^{25}$ On the one hand, since smoking rates are higher among rural residents (approx. 18\% currently), smoking bans may have the capacity to result in larger (absolute) declines in smoking rates and lead to stronger health effects for children. However, rural residents may also be less likely to spend time in restaurants or bars, which may moderate the effects of smoking restrictions, and the lower population density may further moderate any negative effects on smoking through peer effects and the social multiplier. Rural and urban residents also differ in their addictive

\footnotetext{
${ }^{24}$ When the analyses are restricted to ever-treated units, the lead effects test, for instance, whether counties that are $0-4$ years away from implementing a ban exhibit a different time trend than counties that are more than four years from implementing (but do eventually implement within our time period).

${ }^{25}$ Stratifying based on a locality's smoking rate would not be appropriate as the prevalence of smoking (and the change in this prevalence) is endogenous to the smoking bans.
} 
nicotine stock, which may lead to differential responses to the bans. Hence, a priori, it is unclear whether a strict smoking ban would have stronger or weaker effects in rural vs. urban counties. Overall, we do not find consistent differences in the estimates across the urban vs. rural samples. Some results were larger in magnitude among the rural sample, which may be because of higher smoking prevalence in rural compared to urban areas, and some of our estimates, notably effects on infant health (though differences in some cases were not statistically significant) were larger among the urban samples. A key point is that our results do not appear to be uniformly driven by children residing in rural areas or urban areas.

Another concern relates to the possibility that the earliest smoking bans may be endogenous if the most health-conscious communities are the early adopters. We re-estimated all models for infant health over a restricted time period (1995-2009), following Gao and Baughman (2017), thereby bypassing the early adopters. Truncating the end period of the sample to 2009 (and alternately to 2007) further addresses the concern of potential bias due to a change in the composition of births if the recession and subsequent recovery impacted fertility decisions. Our estimates are fully robust to limiting the sample period. ${ }^{26}$

Next, we consider the influence of prenatal alcohol consumption on birth outcomes. Given that some studies suggest that smoking bans in bars may have reduced smoking among heavy drinkers (Anger et al. 2011; and Carton et al., 2016), we test whether prenatal alcohol consumption

\footnotetext{
${ }^{26}$ Gao and Baughman (2017) find that the smoking bans are not associated with any significant improvement in infant health based on data from 1995-2009. Given that we continue to find a clinically meaningful and statistically significant increase in birthweight and reduction in low birthweight even when we restrict the sample period, the choice of the sample period is clearly not the primary driver of the difference in the results. The difference is likely due to how the bans are codified. We find significantly larger improvements in infant health when comparing localities with a combined comprehensive smoking bans in all three venues relative to localities with no bans at all. In contrast, Gao and Baughman (2017) consider the effects of any comprehensive ban (in at least one venue) relative to all other localities (which may have no bans or limited bans); these effects would expectedly be muted. Another factor that may have attenuated effects in Gao and Baughman (2017) is that they do not appear to exploit the month of conception in matching the bans to the birth records. Instead, they use a more aggregate measure, all births in year $\mathrm{t}$ in a giving locality are matched with the county share of the population that is protected by a ban in that year.
} 
may be mediating the effects of the comprehensive bans on infant health. ${ }^{27}$ First, we use prenatal alcohol use as an outcome and test whether a comprehensive smoking ban all three venues influences maternal drinking. We find the estimate to be close to zero in magnitude and insignificant. Second, we estimate our model for 1990-2006 (period over which prenatal alcohol use is available in the natality files) and alternately include/exclude measures of prenatal alcohol use. The estimated effects of comprehensive smoking bans remains robust. ${ }^{28}$ We are not able to test for mediating effects operating through changes in the use of other complementary substances (for instance, prenatal marijuana or other drug use). However, if present, these effects are likely to be secondary or tertiary, and prenatal smoking and exposure to ETS remain the most plausible firstorder channels of effects.

Finally, we test a combined index of respiratory problems and a more general index of health problems in the NHIS, in order to boost statistical power and guard against the type I error associated with multiple testing. ${ }^{29}$ Following Kling, Liebman and Katz (2007), we construct a standardized index combining the past-year respiratory conditions and a broader measure that also adds the other past-year measures of health from the NHIS (listed in Table 2). These models indicate that a comprehensive ban in all venues significantly reduces respiratory problems and health problems among children in low-educated households by 0.06 to 0.08 standard deviation; as with our disaggregated results, the health improvements are magnified in children who had previously been diagnosed with asthma (0.2 standard deviation improvement).

\section{Discussion}

\footnotetext{
${ }^{27}$ Adult alcohol consumption would not influence child respiratory health, and hence this analysis is limited to the birth outcomes.

28 This exercise is meant to be suggestive and should be interpreted with caution given that measures of prenatal alcohol use in the natality data are not very reliable and only available until 2006 (and until 2002 in the case of a more detailed measure of number of drinks consumed).

${ }^{29}$ We thank an anonymous reviewer for this suggestion.
} 
As evidence of the negative effects of environmental tobacco smoke (ETS) has mounted, an increasingly popular public policy response has been to impose restrictions on smoking through comprehensive smoking bans. The CDC and IOM, amidst evidence that smoking bans reduce smoking prevalence and adult non-smokers' exposure to ETS, recommend that states and localities enact complete bans on smoking in all non-residential indoor locations, including worksites, restaurants, and bars. However, a key link necessary for a comprehensive evaluation of the effectiveness of smoking bans has been understudied in the literature including the CDC and IOM reports. Specifically, very few studies have assessed how smoking bans impact the health of children and infants. The rationale for smoke-free laws implicitly presumes there are public health gains from reducing adult cigarette consumption and declines in adult ETS exposure that extend to children. This presumption may be incorrect if smokers shift from consuming cigarettes at 100\% smoke-free work and other public places to smoking at home (when children, infants, or pregnant women are present). Such displacement as a result of comprehensive smoking bans can potentially increase the prevalence of smoking at home and lead to higher ETS exposures among children. On the one hand, decreases in adult smoking prevalence as a result of the smoking bans may reduce ETS exposure among children, infants, and pregnant women. Without information on the link between smoking bans, potential shifts in smoking to the home, and the impact on child and infant health, either the costs or benefits of interventions banning smoking may be understated, which in turn may skew the proper evaluation of such policies.

Based on the most complete information on comprehensive smoking bans, which includes both state-level bans as well as local county and city-level bans, we find robust evidence that the health benefits of these restrictions, which prior studies have estimated for adults, also extend to children and infants, particularly infants and children in low-educated households. ${ }^{30}$ The effects are

\footnotetext{
${ }^{30}$ Our estimates are qualitatively consistent with Simon (2014), who finds that tobacco control policy in the form of higher cigarette taxes during the prenatal period imparts longer-term effects on the health of older children.
} 
largest when the restrictions are the most binding and do not allow for any exemptions such as separate designated smoking areas. We find minimal to weak effects of such limited bans which generally have several exemptions and qualifications. The effects are also compounded when all three comprehensive restrictions - in worksites, restaurants, and freestanding bars - are in place in a given locality. Banning smoking in all three venues limits available options for smokers to carry on the habit, thus increasing non-monetary costs, which in turn raises their effectiveness in reducing smoking behaviors and thus ETS. We also find that most of the realized (about $80-85 \%$ ) health improvements in infant health are driven by a potential reduction in ETS exposure by pregnant women, with the remainder driven by a direct reduction in prenatal smoking. The effect magnitudes of a comprehensive smoking ban in all venues (workplace, restaurants, and bars), relative to no bans at all, on birthweight and low birthweight are commensurate with between a \$1-\$2 increase in the cigarette excise tax.

While these improvements in infant and child health are mostly driven by potentially decreased exposure to ETS, it was also not clear whether these improvements are being moderated by possible displacement of smoking to inside the home as more external places ban smoking. This study provided some of the first direct estimates on displacement. We do not find any evidence that adults are shifting their smoking behaviors to inside the home where children may be present. If anything, we find significant evidence of a decrease in the likelihood that smoking occurs inside the home among households with children, consistent with an overall reduction in the addictive stock and an overall reduction in smoking behaviors.

Currently, about $60 \%$ of the population resides in localities which have completely banned smoking in worksites, restaurants, and freestanding bars. As our estimates suggest strongest effects for this compounded ban, there still remains considerable room for cumulative smoking restrictions to take hold, which would have positive external spillovers on infant and child health. Our effect 
magnitudes imply that expanding this coverage to $100 \%$ of the population can prevent between approximately 1,110 - 1,750 low birthweight births among low-educated mothers, resulting in potential economic cost savings of up to $\$ 111$ million annually (in current dollars). ${ }^{31}$ Health improvements among older children would add to these economic benefits. Furthermore, given that our estimates suggest stronger health improvements for children born in low-educated households, cumulative smoking restrictions may play a role in flattening the socioeconomic gradient in infant and child health.

${ }^{31}$ See http://www.urbanchildinstitute.org/sites/all/files/databooks/07_CostOfPre-TermBirths_TUCI2008.ii.pdf for cost estimates of low birthweight and preterm births. 


\section{References}

Adams, Scott, Chad Cotti. 2008. "Drunk Driving after the Passage of Smoking Bans in Bars,” Journal of Public Economics, 92(5-6): 1288-1305.

Adda, Jerome, Francesca Cornaglia. 2006. “Taxes, Cigarette Consumption, and Smoking Intensity,” American Economic Review, 96(4), 1013-28.

Adda, Jerome, Francesca Cornaglia. 2010. “The Effects of Bans and Taxes on Passive Smoking,” American Economic Journal: Applied Economics, 2(1), 1-32.

Almond, Douglas, Hilary Hoynes, Diane Whitmore Schanzenbach. 2011. "Inside the War on Poverty: The Impact of Food Stamps on Birth Outcomes" Review of Economics and Statistics, 93(2): 387-403.

Anger, Silke, Kvasnicka M, Siedler T. 2011. “One last puff? Public smoking bans and Smoking Behavior,” Journal of Health Economics, 30(3): 591-601.

Angrist, Joshua D., Jörn-Steffen Pischke. 2009. Mostly Harmless Econometrics, Princeton, New Jersey: Princeton University Press.

Been, J.V., Nurmatov, U.B., Cox, B., Nawrot, T.S., Van Schayck, C.P. and Sheikh, A., 2014. Effect of smoke-free legislation on perinatal and child health: a systematic review and meta-analysis. The Lancet, 383(9928), pp.1549-1560.

Bonnie Richard J., Kathleen Stratton, and Robert B. Wallace, 2007a, Ending the Tobacco Problem: Blueprint for the Nation, Washington, D.C., The National Academies Press.

Bonnie Richard J., Kathleen Stratton, and Robert B. Wallace, 2007b, Committee on Reducing Tobacco Use: Strategies, Barriers, and Consequences, Washington, D.C., The National Academies Press.

Brauer, M. and Mannetje, A.T., 1998. Restaurant smoking restrictions and environmental tobacco smoke exposure. American Journal of Public Health, 88(12), pp.1834-1836.

Carton, Thomas W., Michael Darden, John Levendis, Sang H. Lee, and Iben Ricket. 2016. "Comprehensive Indoor Smoking Bans and Smoking Prevalence: Evidence from BRFSS." American Journal of Health Economics. 2(4):535-556.

Cesaroni G, Forastiere F, Agabiti N, Valente P, Zuccaro P, Perucci C “Effect of the Italian Smoking Ban on Population Rates of Acute Coronary Events,” Preventive Cardiology, 2008;117:1183-1188.

Colman, G., Grossman, M. and Joyce, T., 2003. The effect of cigarette excise taxes on smoking before, during and after pregnancy. Journal of Health Economics, 22(6), pp.1053-1072.

Colman, G.J. and Joyce, T., 2003. Trends in smoking before, during, and after pregnancy in ten states. American journal of preventive medicine, 24(1), pp.29-35. 
Colman, Gregory, and Dahlia Remler. 2008. "Vertical Equity Consequences of Very High Cigarette Tax Increases: If the Poor are the Ones Smoking, How Could Cigarette Tax Increases be Progressive?” Journal of Policy Analysis and Management. 27(2): 376-400.

Eisner, Mark D., Alexander K. Smith, and Paul D. Blanc. 1998. "Bartenders' Respiratory Health After Establishment of Smoke-Free Bars and Taverns,” Journal of the American Medical Association. 280:1909-1914.

Evans, William N., Matthew C. Farrelly, Edward Montgomery. 1999. “Do Workplace Smoking Bans Reduce Smoking?” American Economic Review, 89:728-747.

Evans, William and Jeanne S. Ringel. 1999. “Can Higher Cigarette Taxes Improve Birth Outcomes?” Journal of Public Economics. 72: 135-154.

Faber, T., Been, J.V., Reiss, I.K., Mackenbach, J.P. and Sheikh, A., 2016. Smoke-free legislation and child health. NPJ primary care respiratory medicine, 26, p.16067.

Farrelly, Matthew C., William N. Evans, and Anderw E. Sfekas. 1999. "The Impact of Workplace Smoking Bans: Results from a National Survey,” Tobacco Control. 8(3):272-277.

Fichtenberg, Caroline M., Stanton A. Glantz. 2002. "Effect of Smoke-free Workplaces on Smoking Behaviour: Systematic Review.” British Medical Journal. 325(7357):188.

Gao, Jiang, and Reagan A. Baughman. 2017. "Do Smoking Bans Improve Infant Health? Evidence from U.S. Births: 1995-2009,” Eastern Economic Journal. 43(472-495).

Goodman, Patrick, Michelle Agnew, Marie McCaffrey, Gillian Paul, and Luke Clancy. 2007. "Effects of the Irish Smoking Ban on Respiratory Health of Bar Workers and Air Quality in Dublin Pubs.” Respiratory and Critical Care Medicine. 175: 840-845.

Hoynes, Hilary, Doug Miller and David Simon. 2015. "Income, the Earned Income Tax Credit, and Infant Health." American Economic Journal: Economic Policy, 7(1): 172-211.

Institute of Medicine. Butler, A.S. and Behrman, R.E. eds., 2007. Preterm birth: causes, consequences, and prevention. National Academies Press.

Klepeis, Neil E., William C. Nelson, Wayne R. Ott, John P. Robinson, Andy M. Tsang, Paul Switzer, Joseph Behar, Stephen C. Hern, and William H. Engelmann. 2001. "The National Human Activity Pattern Survey (NHAPS): a Resource for Assessing Exposure to Environmental Pollutants,” Journal of Exposure Analysis and Environmental Epidemiology. 11(3):231-52.

Kling, J.R., Liebman, J.B. and Katz, L.F., 2007. Experimental analysis of neighborhood effects. Econometrica, 75(1), pp.83-119.

Kvasnicka, M., Siedler, T. and Ziebarth, N.R., 2018. The health effects of smoking bans: Evidence from German hospitalization data. Health economics, 27(11), pp. 1738-1753. 
Leung, Gabriel M., Lai Ming Ho, and Tai Hing Lam. 2013. “The Economic Burden of Environmental Tobacco Smoke in the First Year of Life,” Archives of Disease in Childhood, 88(9): 767-771.

Markowitz, Sara, E. Kathleen Adams, Patricia M, Dietz, Van T. Tong, Viji Kannan. 2013. “Tobacco Control Policies, Birth Outcomes, and Maternal Human Capital.” Journal of Human Capital. 7:130-60.

McGeary, Kerry Anne, Dhaval Dave, Brandy Lipton, Timothy Roeper, “Impact of Comprehensive Smoking Bans on the Health of Infants and Children," National Bureau of Economic Research Working Paper, No. 23995, November 2017.

Meyers David G., John S. Neuberger, and Jianghua He. 2009. "Cardiovascular Effect of Bans on Smoking in Public Places: A Systematic Review and Meta-Analysis,” Journal of the American College of Cardiology. 54:1249- 1255.

Nielsen, S.S., Dills, R.L., Glass, M. and Mueller, B.A., 2014. Accuracy of prenatal smoking data from Washington State birth certificates in a population-based sample with cotinine measurements. Annals of epidemiology, 24(3), pp.236-239.

Northam, S. and Knapp, T.R., 2006. The reliability and validity of birth certificates. Journal of Obstetric, Gynecologic \& Neonatal Nursing, 35(1), pp.3-12.

Orzechowski and Walker. 2012. The Tax Burden on Tobacco: Historical Compilation. Volume 47.

Pesko, M.F., Tauras, J.A., Huang, J. and Chaloupka IV, F.J., 2016. The influence of geography and measurement in estimating cigarette price responsiveness (No. w22296). National Bureau of Economic Research Working Paper Series.

Rayens, M.K., Burkhart, P.V., Zhang, M., Lee, S., Moser, D.K., Mannino, D. and Hahn, E.J., 2008. Reduction in asthma-related emergency department visits after implementation of a smoke-free law. Journal of Allergy and Clinical Immunology, 122(3), pp.537-541.

Seo, Dong-Chul and Mohammed Torabi. 2007. "Reduced Admissions for Acute Myocardial Infarction Associated with a Public Smoking Ban: Matched Controlled Study,” Journal of Drug Education. 37(3):217-226.

Shetty, Kanaka D., Thomas Deleire, Chapin White, and Jayanta Bhattacharya. 2011. "Changes in US hospitalization and mortality rates following smoking bans,” Journal of Policy Analysis and Management. 30(1):6-28.

Siegel, Michael, Alison B. Albers, Debbie Chang, Lisa Beiner and Nancy A. Rigotti. 2005. "Effect of Local Restaurant Smoking Regulations on Progression to Established Smoking Among Youths.” Tobacco Control. 14: 300-306.

Simon, D., 2016. Does early life exposure to cigarette smoke permanently harm childhood welfare? Evidence from cigarette tax hikes. American Economic Journal: Applied Economics, 8(4), pp.12859. 
Stillman, Francis A., Diane M. Becker, Robert T. Swank, Donald Hantula, Hamilton Moses, Stanton Glantz, and H. Richard Waranch. 1990. "Ending smoking at the Johns Hopkins Medical Institutions. An evaluation of Smoking Prevalence and Indoor Air Pollution,” Journal of the American Medical Association. 264(12):1565-1569.

Tong, V.T., Dietz, P.M., Farr, S.L., D'angelo, D.V. and England, L.J., 2013. Estimates of smoking before and during pregnancy, and smoking cessation during pregnancy: comparing two populationbased data sources. Public health reports, 128(3), pp.179-188.

U.S. Department of Health and Human Services. 2006. "The Health Consequences of Involuntary Exposure to Tobacco Smoke: A Report of the Surgeon General.” Atlanta, GA. Centers for Disease Control and Prevention, National Center for Chronic Disease Prevention and Health Promotion, Office on Smoking and Health (Atlanta). (Last Accessed July 4, 2018) https://www.surgeongeneral.gov/library/reports/secondhandsmoke/fullreport.pdf.

U.S. Department of Health and Human Services. 2007. "Best Practices for Comprehensive Tobacco Control Programs - 2007.” Atlanta, GA. Centers for Disease Control and Prevention, National Center for Chronic Disease Prevention and Health Promotion, Office on Smoking and Health. (Last Accessed July 4, 2018) https://www.cdc.gov/tobacco/stateandcommunity/best_practices/pdfs/2014/comprehensive.pdf

U.S. Task Force on Community Preventive Services. 2001. "Recommendations Regarding Interventions to Reduce Tobacco Use and Exposure to Environmental Tobacco Smoke,” American Journal of Preventive Medicine, 20(2 Suppl):10-15.(Last Accessed July 4, 2018)

DOI: https://doi.org/10.1016/S0749-3797(00)00300-7.

Valente, Pasquale, Francesco Forastiere, Antonella Bacosi, Giorgio Cattani, Simonetta Di Carlo, Monica Ferri, Irene Figa-Talamanca, Achille Marconi, Luigi Paoletti, Carlo Perucci and Piergiorgio Zuccaro. 2007. "Exposure to Fine and Ultrafine Particles from Secondhand Smoke in Public Places before and after the Smoking Ban, Italy 2005.” Tobacco Control.16:312-317.

Wehby, George L, Dhaval Dave, and Robert Kaestner. 2016. "Effects of the Minimum Wage on Infant Health,” National Bureau of Economic Research Working Paper, 22373.

Wehby, George L, Allen Wilcox A, and Rolv T. Lie RT. 2013. "The Impact of Cigarette Quitting during Pregnancy on Other Prenatal Health Behaviors.” Review of Economics of the Household. 11(2):211-233. (Last Access July 4, 2018) doi:10.1007/s11150-012-9163-8.

Windham, Gayle, Barabar Hopkins, Laura Fenster, and Shanna H. Swan, 2000. "Prenatal Active or Passive Tobacco Smoke Exposure and the Risk of Preterm Delivery or Low Birth Weight.” Epidemiology, 11(4): 427-433.

Yousey, Yvonne K., 2006. "Household Characteristics, Smoking Bans and Passive Smoke Exposure in Children,” Journal of Pediatric Health Care; 20(2): 98-105. 
Figure 1A: Effects of Comprehensive Smoking Bans in All Venues on Birthweight

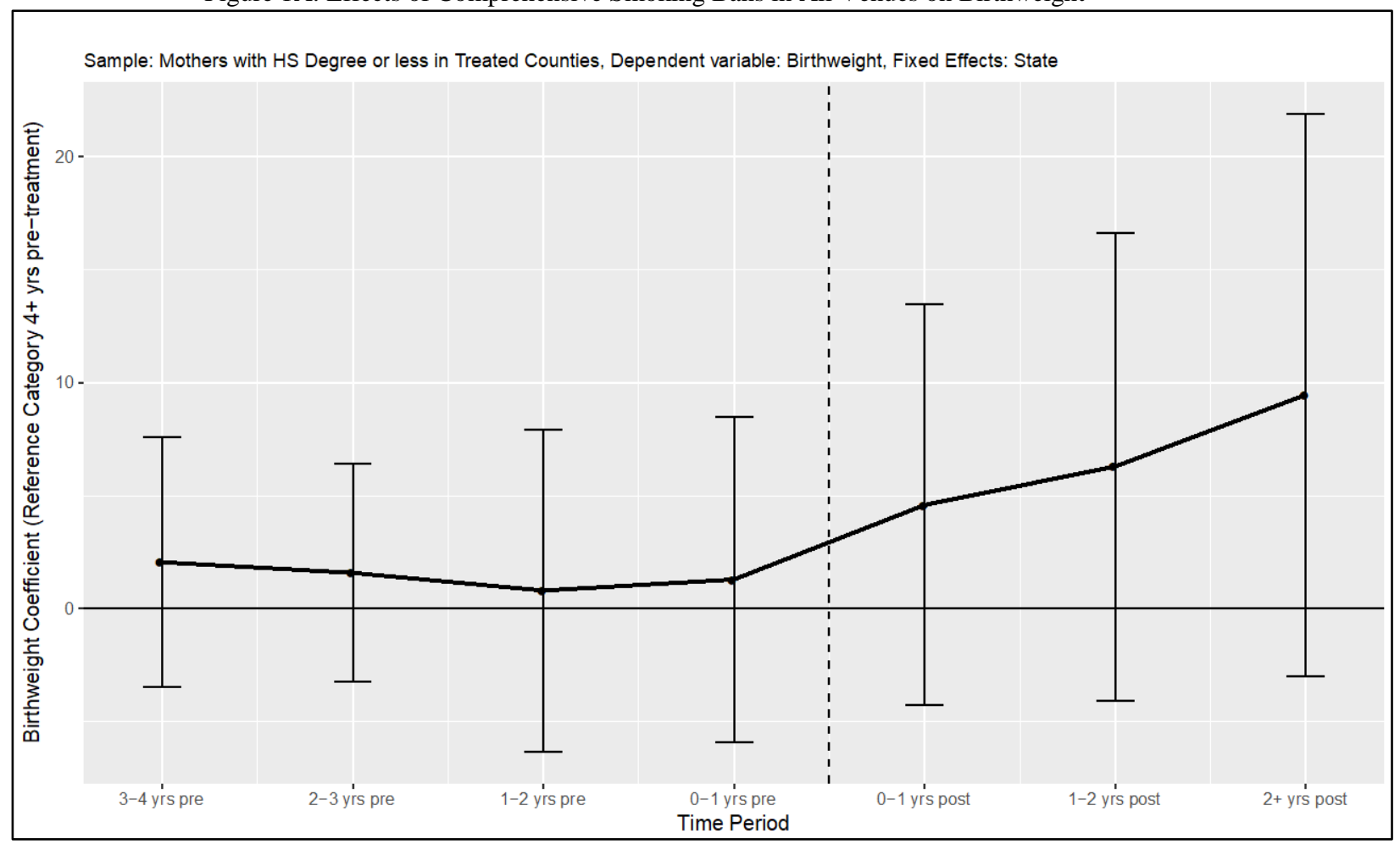

Figure 1B: Effects of Comprehensive Smoking Bans in All Venues on Birthweight

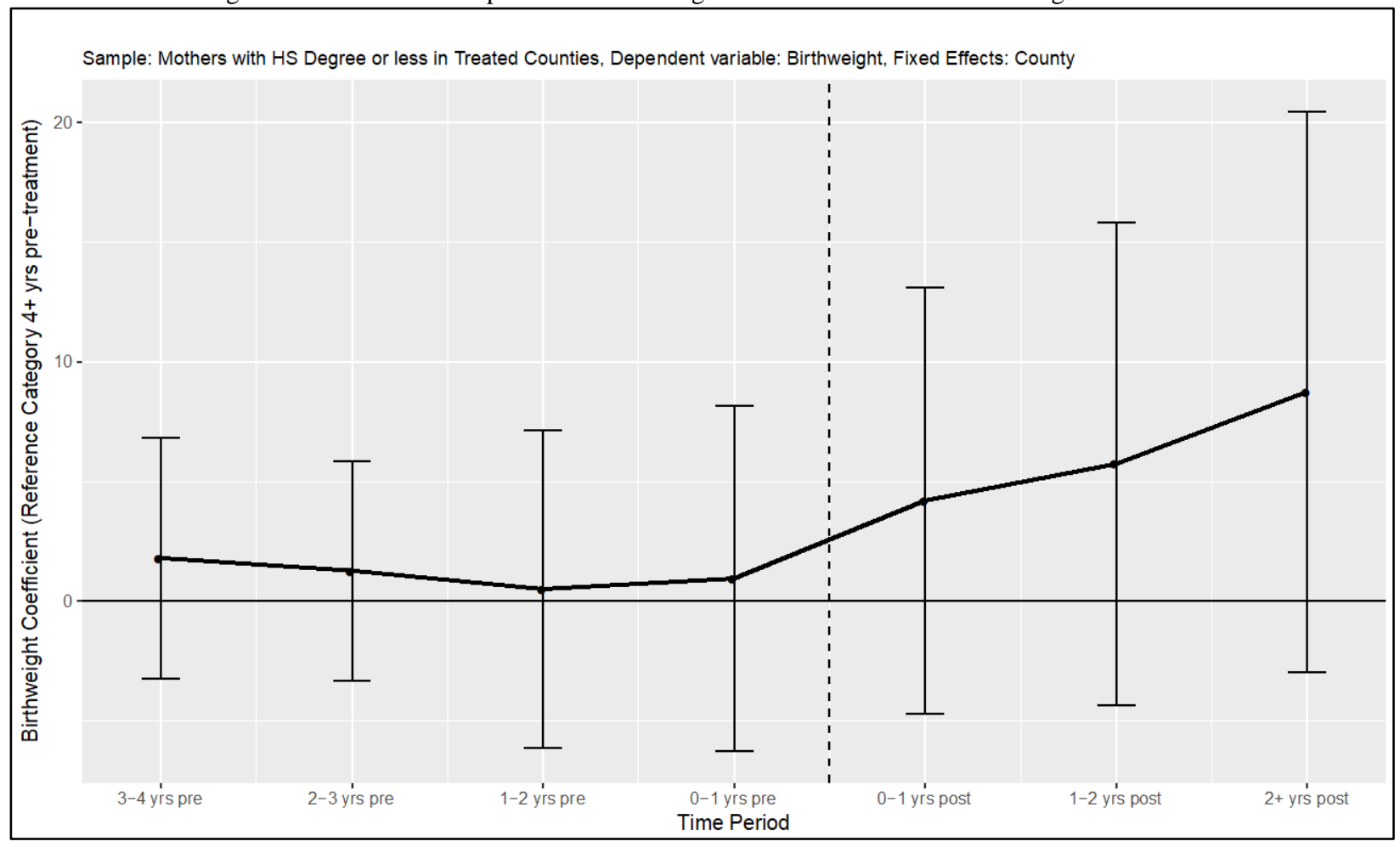


Figure 1C: Effects of Comprehensive Smoking Bans in All Venues on Birthweight

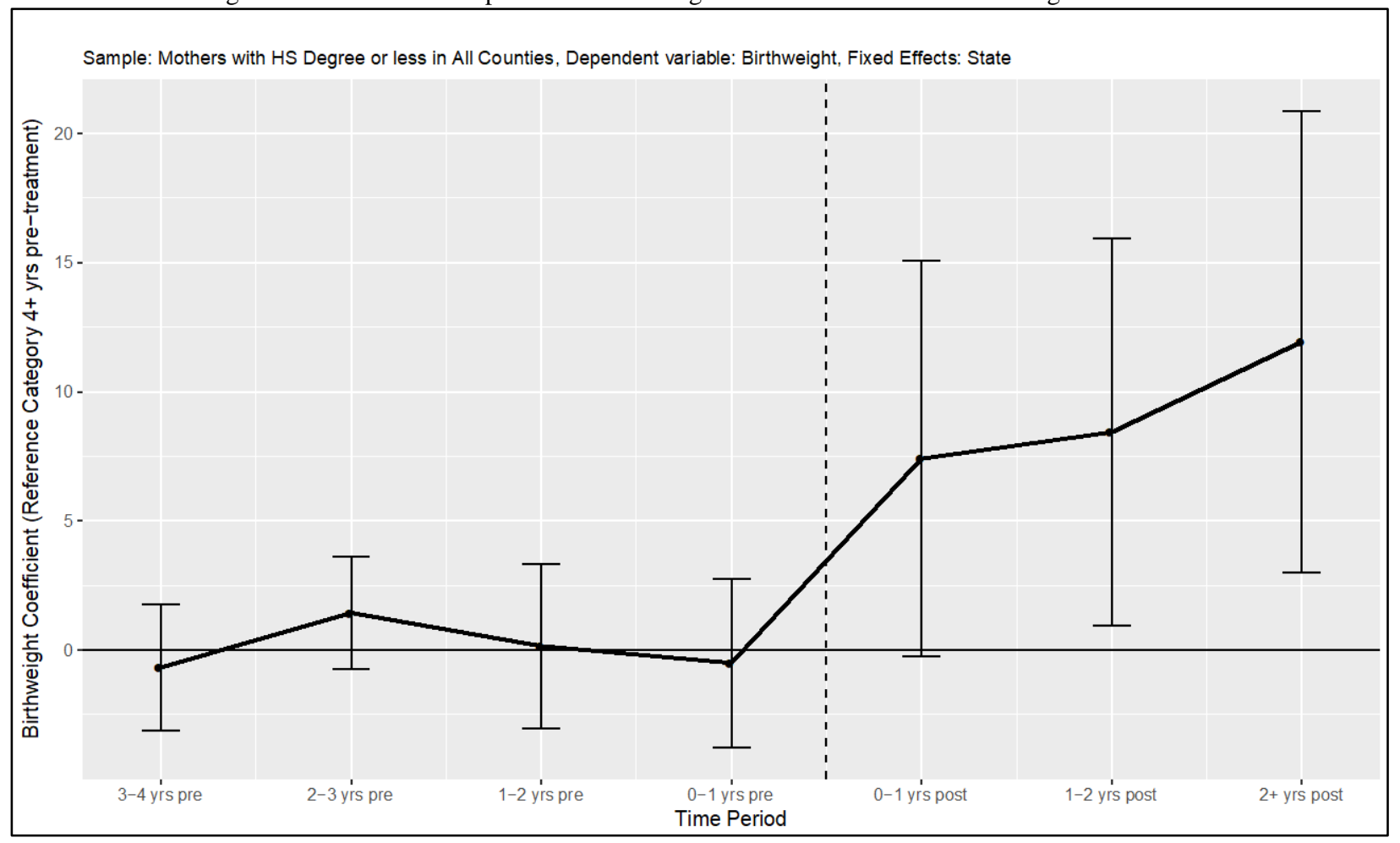

Figure 1D: Effects of Comprehensive Smoking Bans in All Venues on Birthweight

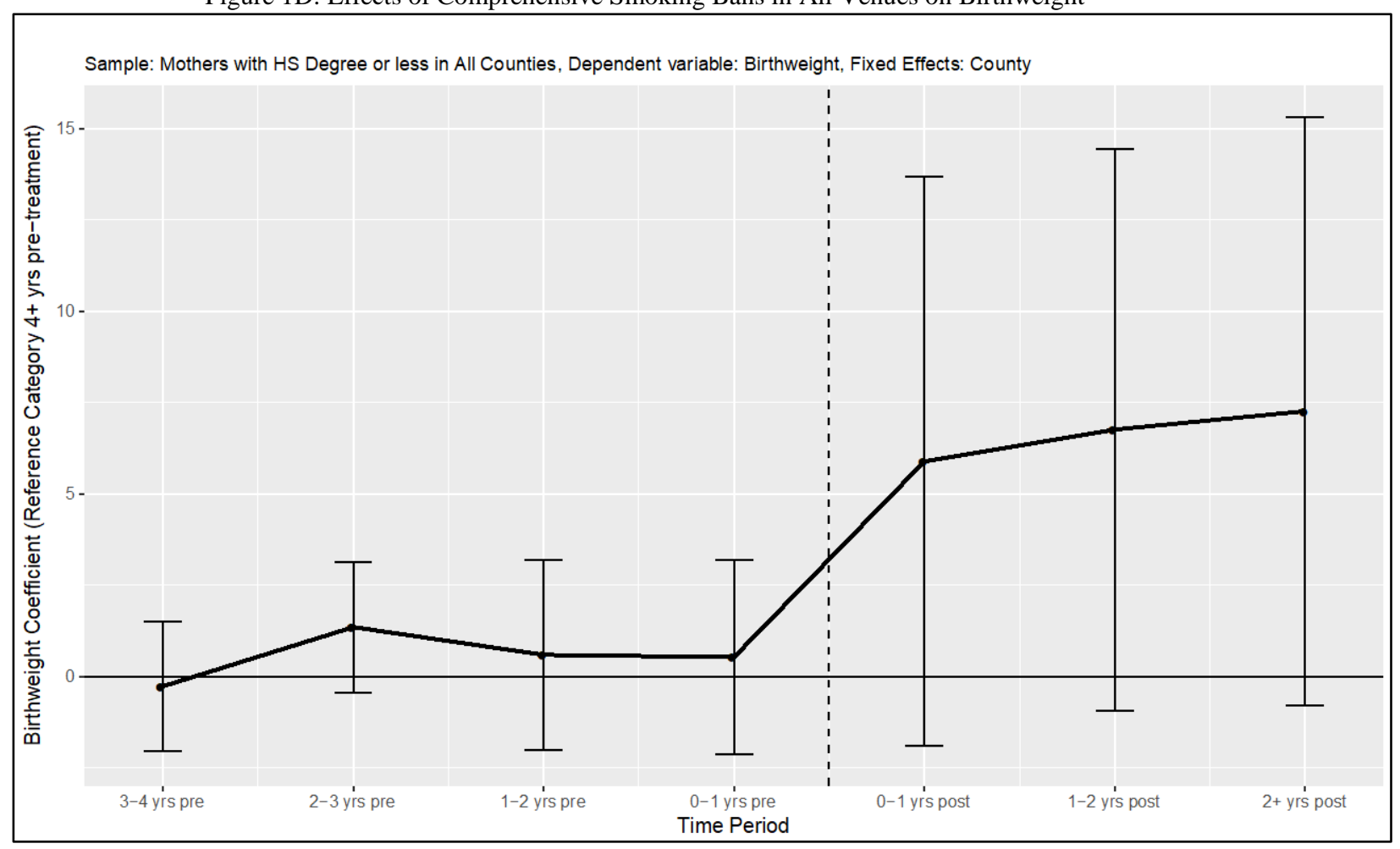


Table 1

Sample means

U.S. Vital Statistics Births 1990-2012

\begin{tabular}{|c|c|c|c|}
\hline Variable & All Births & $\begin{array}{c}\text { Births to mothers } \\
\text { with high school } \\
\text { degree or less } \\
\end{array}$ & $\begin{array}{c}\text { Births to unmarried } \\
\text { mothers with high school } \\
\text { degree or less }\end{array}$ \\
\hline Birthweight (grams) & 3333.832 & 3282603 & 3207640 \\
\hline Low birthweight (birth < 2500 grams) & 0.061 & 0.072 & 0.089 \\
\hline Gestational age (weeks) & 38.864 & 38.824 & 38.694 \\
\hline Preterm birth (gestation < 37 weeks) & 0.101 & 0.115 & 0.134 \\
\hline Fetal growth (Birthweight / gestation) & 85.593 & 84.362 & 82.676 \\
\hline Any prenatal smoking & 0.123 & 0.188 & 0.230 \\
\hline Maternal age & 27.496 & 25.454 & 23.788 \\
\hline Maternal race: White & 0.788 & 0.765 & 0.649 \\
\hline Maternal race: Black & 0.155 & 0.190 & 0.312 \\
\hline Maternal race: Other & 0.056 & 0.045 & 0.039 \\
\hline Maternal ethnicity: Hispanic & 0.174 & 0.257 & 0.265 \\
\hline Maternal educational attainment & 13.024 & 11.024 & 10.953 \\
\hline Married & 0.672 & 0.524 & 0.000 \\
\hline Comprehensive Smoking Ban: All Venues & 0.108 & 0.089 & 0.109 \\
\hline Comprehensive Smoking Ban: Any Venue & 0.196 & 0.168 & 0.200 \\
\hline Comprehensive Smoking Ban: Workplace & 0.136 & 0.114 & 0.142 \\
\hline Limited Smoking Ban: Workplace & 0.402 & 0.397 & 0.400 \\
\hline No Smoking Ban: Workplace & 0.460 & 0.489 & 0.459 \\
\hline Comprehensive Smoking Ban: Restaurant & 0.185 & 0.159 & 0.189 \\
\hline Limited Smoking Ban: Restaurant & 0.274 & 0.263 & 0.264 \\
\hline No Smoking Ban: Restaurant & 0.540 & 0.578 & 0.547 \\
\hline Comprehensive Smoking Ban: Bar & 0.157 & 0.133 & 0.160 \\
\hline Limited Smoking Ban: Bar & 0.063 & 0.060 & 0.066 \\
\hline No Smoking Ban: Bar & 0.779 & 0.808 & 0.774 \\
\hline $\begin{array}{l}\text { Comprehensive Smoking Ban Workplace: } \\
\text { \% population exposed }\end{array}$ & 0.131 & 0.109 & 0.133 \\
\hline $\begin{array}{l}\text { Comprehensive Smoking Ban Restaurant: } \\
\% \text { population exposed }\end{array}$ & 0.190 & 0.166 & 0.197 \\
\hline $\begin{array}{l}\text { Comprehensive Smoking Ban Bar: } \\
\text { \% population exposed }\end{array}$ & 0.164 & 0.140 & 0.170 \\
\hline Real state cigarette excise tax (2014\$) & 0.812 & 0.760 & 0.816 \\
\hline Observations & $70,637,634$ & $34,912,824$ & $16,607,601$ \\
\hline
\end{tabular}

Note: Sample means are reported. Observations represent maximum sample size. For some variables, notably prenatal smoking ( $\mathrm{n}=70,557,124$ for all births), sample sizes are smaller due to missing information (see text). 
Table 2

Child Health Outcome Means

Children Ages < 18

National Health Interview Surveys, 1998-2013

\begin{tabular}{|lcccc|}
\hline Outcome & & & & \\
Hay fever, past year & 0.1007 & 0.2309 & 0.0786 & 0.1831 \\
Any respiratory allergies, past year & 0.1760 & 0.4261 & 0.1436 & 0.3611 \\
Ever diagnosed with asthma & 0.1297 & --- & 0.1311 & -- \\
Asthma attack, past year & 0.0557 & 0.4299 & 0.0535 & 0.4084 \\
ER visit for asthma, past year & 0.0186 & 0.1438 & 0.0210 & 0.1605 \\
ER visit for any reason, past year & 0.2046 & 0.3173 & 0.2258 & 0.3555 \\
3 or more ear infections, past year & 0.0621 & 0.0889 & 0.0645 & 0.1066 \\
Excellent or very good health & 0.8376 & 0.7063 & 0.7656 & 0.6152 \\
Fair or poor health & & & & \\
\hline Sample & & & & \\
\hline Observations & 0.0184 & 0.0597 & 0.0283 & 0.0887 \\
\hline
\end{tabular}

Notes: The sample includes children under age 18 (including children who have ever received an asthma diagnosis) with complete demographic information interviewed between 1998 and 2013. Estimates incorporated population weights available from the National Center for Health Statistics. 
Table 3

Effects of Comprehensive Smoking Bans in All Venues (Workplace, Restaurants, and Bars) on Infant Health

Mothers' Education: High school graduate or less Births 1990-2012

\begin{tabular}{|c|c|c|c|c|c|c|c|c|c|c|}
\hline Panel A & \multicolumn{10}{|c|}{ Reference Group: All others } \\
\hline $\begin{array}{l}\text { Model } \\
\text { Outcome }\end{array}$ & $\begin{array}{c}\text { (1) } \\
\text { Birthweight }\end{array}$ & $\begin{array}{c}\text { (2) } \\
\text { Low } \\
\text { Birthweight }\end{array}$ & $\begin{array}{c}(3) \\
\text { Gestation }\end{array}$ & $\begin{array}{c}\text { (4) } \\
\text { Preterm }\end{array}$ & $\begin{array}{c}\text { (5) } \\
\text { Fetal } \\
\text { Growth }\end{array}$ & $\begin{array}{c}\text { (6) } \\
\text { Birthweight }\end{array}$ & $\begin{array}{c}\text { (7) } \\
\text { Low } \\
\text { Birthweight }\end{array}$ & $\begin{array}{c}(8) \\
\text { Gestation }\end{array}$ & $\begin{array}{c}\text { (9) } \\
\text { Preterm }\end{array}$ & $\begin{array}{c}(10) \\
\text { Fetal } \\
\text { Growth }\end{array}$ \\
\hline & \multicolumn{10}{|c|}{ Models with State and Year Fixed Effects } \\
\hline Comprehensive Ban - All Venues & $\begin{array}{c}11.3873^{* *} \\
(4.5292)\end{array}$ & $\begin{array}{c}-0.0020^{* *} \\
(0.0007)\end{array}$ & $\begin{array}{c}0.0548 * * \\
(0.0211)\end{array}$ & $\begin{array}{l}-0.0007 \\
(0.0013)\end{array}$ & $\begin{array}{c}0.1842 * * \\
(0.0748)\end{array}$ & $\begin{array}{c}10.8746 * * \\
(4.8759)\end{array}$ & $\begin{array}{c}-0.0018^{* *} \\
(0.0008)\end{array}$ & $\begin{array}{c}0.0544 * * \\
(0.0211)\end{array}$ & $\begin{array}{c}-0.0006 \\
(0.0014)\end{array}$ & $\begin{array}{c}0.1720^{*} \\
(0.0860)\end{array}$ \\
\hline Cigarette Tax & $\begin{array}{c}6.0697 * * * \\
(2.0876)\end{array}$ & $\begin{array}{c}-0.0016^{* * *} \\
(0.0005)\end{array}$ & $\begin{array}{c}0.0309 * * \\
(0.0134)\end{array}$ & $\begin{array}{c}-0.0017^{*} \\
(0.0009)\end{array}$ & $\begin{array}{c}0.0963 * * \\
(0.0427)\end{array}$ & $\begin{array}{c}5.3522 * * \\
(2.1037)\end{array}$ & $\begin{array}{c}-0.0015^{* * *} \\
(0.0005)\end{array}$ & $\begin{array}{c}0.0303 * * \\
(0.0134)\end{array}$ & $\begin{array}{c}-0.0016^{*} \\
(0.0009)\end{array}$ & $\begin{array}{c}0.0788 * \\
(0.0419)\end{array}$ \\
\hline & \multicolumn{10}{|c|}{ Models with County and Year Fixed Effects } \\
\hline Comprehensive Ban - All Venues & $\begin{array}{l}6.5172 * \\
(3.6550)\end{array}$ & $\begin{array}{l}-0.0015 \\
(0.0009)\end{array}$ & $\begin{array}{l}0.0394 * \\
(0.0208)\end{array}$ & $\begin{array}{c}0.0005 \\
(0.0011)\end{array}$ & $\begin{array}{c}0.1005 \\
(0.0615)\end{array}$ & $\begin{array}{c}5.1039 \\
(3.6560)\end{array}$ & $\begin{array}{c}-0.0012 \\
(0.0009)\end{array}$ & $\begin{array}{l}0.0383^{*} \\
(0.0206)\end{array}$ & $\begin{array}{c}0.0007 \\
(0.0011)\end{array}$ & $\begin{array}{c}0.0666 \\
(0.0663)\end{array}$ \\
\hline Cigarette Tax & $\begin{array}{c}6.9733 * * * \\
(2.0664)\end{array}$ & $\begin{array}{c}-0.0019 * * * \\
(0.0005)\end{array}$ & $\begin{array}{l}0.0341 * * \\
(0.0131)\end{array}$ & $\begin{array}{c}-0.0022 * * \\
(0.0008)\end{array}$ & $\begin{array}{c}0.1126^{* * * *} \\
(0.0421)\end{array}$ & $\begin{array}{c}5.7844 * * * \\
(2.0789)\end{array}$ & $\begin{array}{c}-0.0016 * * * \\
(0.0005)\end{array}$ & $\begin{array}{c}0.0331 * * \\
(0.0132)\end{array}$ & $\begin{array}{c}-0.0020^{* *} \\
(0.0009)\end{array}$ & $\begin{array}{c}0.0839 * * \\
(0.0412)\end{array}$ \\
\hline Control for Maternal Smoking & No & No & No & No & No & Yes & Yes & Yes & Yes & Yes \\
\hline Observations & $34,655,278$ & $34,673,641$ & $34,607,278$ & $34,664,996$ & $34,584,285$ & $34,655,278$ & $34,673,641$ & $34,607,278$ & $34,664,996$ & $34,584,285$ \\
\hline Panel B & \multicolumn{10}{|c|}{ Reference Group: No bans in any venue } \\
\hline $\begin{array}{l}\text { Model } \\
\text { Outcome }\end{array}$ & $\begin{array}{c}\text { (1) } \\
\text { Birthweight }\end{array}$ & $\begin{array}{c}(2) \\
\text { Low } \\
\text { Birthweight }\end{array}$ & $\begin{array}{c}\text { (3) } \\
\text { Gestation }\end{array}$ & $\begin{array}{c}(4) \\
\text { Preterm }\end{array}$ & $\begin{array}{c}\text { (5) } \\
\text { Fetal } \\
\text { Growth }\end{array}$ & $\begin{array}{c}\text { (6) } \\
\text { Birthweight }\end{array}$ & $\begin{array}{c}\text { (7) } \\
\text { Low } \\
\text { Birthweight }\end{array}$ & $\begin{array}{c}\text { (8) } \\
\text { Gestation }\end{array}$ & $\begin{array}{c}\text { (9) } \\
\text { Preterm }\end{array}$ & $\begin{array}{c}(10) \\
\text { Fetal } \\
\text { Growth }\end{array}$ \\
\hline & \multicolumn{10}{|c|}{ Models with State and Year Fixed Effects } \\
\hline Comprehensive Ban - All Venues & $\begin{array}{c}18.1501 * * \\
(7.5713)\end{array}$ & $\begin{array}{c}-0.0030 * \\
(0.0018)\end{array}$ & $\begin{array}{c}0.0930^{* *} \\
(0.0393)\end{array}$ & $\begin{array}{l}-0.0026 \\
(0.0023)\end{array}$ & $\begin{array}{c}0.2836 * * \\
(0.1242)\end{array}$ & $\begin{array}{c}16.6842^{* *} \\
(7.5967)\end{array}$ & $\begin{array}{c}-0.0027 \\
(0.0018)\end{array}$ & $\begin{array}{c}0.0919 * * \\
(0.0391)\end{array}$ & $\begin{array}{c}-0.0024 \\
(0.0023)\end{array}$ & $\begin{array}{l}0.2482 * \\
(0.1299)\end{array}$ \\
\hline Cigarette Tax & $\begin{array}{c}5.2336 * * \\
(2.3012)\end{array}$ & $\begin{array}{c}-0.0017^{* * *} \\
(0.0005)\end{array}$ & $\begin{array}{l}0.0389 * \\
(0.0201)\end{array}$ & $\begin{array}{c}-0.0018^{*} \\
(0.0010)\end{array}$ & $\begin{array}{l}0.0591 * \\
(0.0346)\end{array}$ & $\begin{array}{l}4.6970 * \\
(2.6923)\end{array}$ & $\begin{array}{c}-0.0016^{* *} \\
(0.0007)\end{array}$ & $\begin{array}{l}0.0385 * \\
(0.0202)\end{array}$ & $\begin{array}{l}-0.0017 \\
(0.0011)\end{array}$ & $\begin{array}{c}0.0462 \\
(0.0443)\end{array}$ \\
\hline & \multicolumn{10}{|c|}{ Models with County and Year Fixed Effects } \\
\hline Comprehensive Ban - All Venues & $\begin{array}{l}12.5871^{*} \\
(6.3315)\end{array}$ & $\begin{array}{c}-0.0024 \\
(0.0017)\end{array}$ & $\begin{array}{c}0.0841 * * * \\
(0.0311)\end{array}$ & $\begin{array}{l}-0.0019 \\
(0.0018)\end{array}$ & $\begin{array}{c}0.1652 \\
(0.1077)\end{array}$ & $\begin{array}{l}10.5024 \\
(6.6304)\end{array}$ & $\begin{array}{l}-0.0019 \\
(0.0018)\end{array}$ & $\begin{array}{c}0.0826 * * \\
(0.0312)\end{array}$ & $\begin{array}{l}-0.0016 \\
(0.0019)\end{array}$ & $\begin{array}{c}0.1148 \\
(0.1173)\end{array}$ \\
\hline Cigarette Tax & $\begin{array}{c}6.2166 * * * \\
(1.9605)\end{array}$ & $\begin{array}{c}-0.0021 * * * \\
(0.0005)\end{array}$ & $\begin{array}{c}0.0458 * * \\
(0.0181)\end{array}$ & $\begin{array}{c}-0.0025^{* *} \\
(0.0009)\end{array}$ & $\begin{array}{c}0.0713^{* * *} \\
(0.0258)\end{array}$ & $\begin{array}{l}4.5232 * \\
(2.3969)\end{array}$ & $\begin{array}{c}-0.0017 * * \\
(0.0007)\end{array}$ & $\begin{array}{c}0.0445^{* *} \\
(0.0183)\end{array}$ & $\begin{array}{c}-0.0023^{* *} \\
(0.0010)\end{array}$ & $\begin{array}{c}0.0304 \\
(0.0349)\end{array}$ \\
\hline Control for Maternal Smoking & No & No & No & No & No & Yes & Yes & Yes & Yes & Yes \\
\hline Observations & $18,156,650$ & $18,166,551$ & $18,129,267$ & $18,162,787$ & $18,118,007$ & $18,156,650$ & $18,166,551$ & $18,129,267$ & $18,162,787$ & $18,118,007$ \\
\hline
\end{tabular}

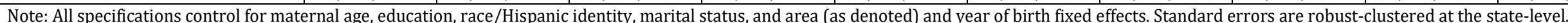

Standard errors are clustered at the state level and reported in parentheses. Asterisks denote statistical significance as follows: ${ }^{* *} p$-value $\leq 0.01$; ${ }^{* *} 0.01<p$-value $\leq 0.05$; ${ }^{*} 0.05<p$-value $\leq 0.10$. 
Table 4

Timing of Response to Comprehensive Smoking Bans in All Venues - Event Study Analysis Mothers' Education: High school graduate or less

Births 1990-2012

Panel A: Ever-Treated Counties

\begin{tabular}{|c|c|c|c|c|}
\hline \multirow{2}{*}{$\begin{array}{l}\text { Panel A } \\
\text { Model }\end{array}$} & \multicolumn{2}{|c|}{ Birthweight } & \multicolumn{2}{|c|}{ Low Birthweight } \\
\hline & 1 & 2 & 3 & 4 \\
\hline & \multicolumn{4}{|c|}{ Time periods pre-implementation (Lead effects) } \\
\hline 4+ Years pre-policy & (Ref) & (Ref) & (Ref) & (Ref) \\
\hline 3-4 Years pre-policy & 2.0506 & 1.8098 & 0.0003 & 0.0000 \\
\hline & $(2.8231)$ & (2.5659) & $(0.0007)$ & $(0.0007)$ \\
\hline 2-3 Years pre-policy & 1.5784 & 1.2764 & 0.0001 & -0.0003 \\
\hline & $(2.4663)$ & $(2.3378)$ & $(0.0007)$ & $(0.0008)$ \\
\hline 1-2 Years pre-policy & $\begin{array}{c}0.7941 \\
(3.6351)\end{array}$ & $\begin{array}{c}0.5080 \\
(3.3825)\end{array}$ & $\begin{array}{c}0.0007 \\
(0.0009)\end{array}$ & $\begin{array}{c}0.0002 \\
(0.0010)\end{array}$ \\
\hline \multirow[t]{3}{*}{ 0-1 Year pre-policy } & 1.2857 & 0.9534 & 0.0008 & 0.0003 \\
\hline & $(3.6675)$ & $(3.6743)$ & $(0.0009)$ & $(0.0011)$ \\
\hline & \multicolumn{4}{|c|}{ Time periods post-implementation (Post-policy effects) } \\
\hline 0-1 Year post-policy & $\begin{array}{c}4.5814 \\
(4.5289)\end{array}$ & $\begin{array}{c}4.2098 \\
(4.5490)\end{array}$ & $\begin{array}{c}-0.0004 \\
(0.0010)\end{array}$ & $\begin{array}{c}-0.0010 \\
(0.0013)\end{array}$ \\
\hline 1-2 Years post-policy & 6.2924 & 5.7430 & -0.0002 & -0.0009 \\
\hline & $(5.2840)$ & $(5.1570)$ & $(0.0014)$ & $(0.0015)$ \\
\hline 2+ Years post-policy & 9.4698 & 8.7585 & -0.0005 & -0.0014 \\
\hline & $(6.3525)$ & $(5.9783)$ & $(0.0017)$ & $(0.0020)$ \\
\hline Year Indicators & Yes & Yes & Yes & Yes \\
\hline Area Fixed Effects & State & County & State & County \\
\hline Observations & $11,222,462$ & $11,222,462$ & $11,222,462$ & $11,229,539$ \\
\hline
\end{tabular}

Panel B: All Counties

\begin{tabular}{|c|c|c|c|c|}
\hline \multirow{2}{*}{$\begin{array}{l}\text { Panel B } \\
\text { Model }\end{array}$} & \multicolumn{2}{|c|}{ Birthweight } & \multicolumn{2}{|c|}{ Low Birthweight } \\
\hline & 1 & 2 & 3 & 4 \\
\hline & \multicolumn{4}{|c|}{ Time periods pre-implementation (Lead effects) } \\
\hline 4+ Years pre-policy & (Ref) & (Ref) & (Ref) & (Ref) \\
\hline \multirow[t]{2}{*}{ 3-4 Years pre-policy } & -0.6732 & -0.2636 & 0.0004 & 0.0003 \\
\hline & $(1.2408)$ & (0.8974) & $(0.0003)$ & $(0.0003)$ \\
\hline \multirow[t]{2}{*}{ 2-3 Years pre-policy } & 1.4417 & 1.3588 & -0.0003 & -0.0003 \\
\hline & $(1.1080)$ & (0.9099) & $(0.0003)$ & $(0.0003)$ \\
\hline \multirow[t]{2}{*}{ 1-2 Years pre-policy } & 0.1592 & 0.5995 & -0.0001 & -0.0002 \\
\hline & (1.6209) & (1.3225) & $(0.0004)$ & $(0.0004)$ \\
\hline \multirow[t]{3}{*}{ 0-1 Year pre-policy } & -0.5002 & 0.5354 & -0.0000 & -0.0002 \\
\hline & $(1.6643)$ & $(1.3515)$ & $(0.0004)$ & $(0.0004)$ \\
\hline & \multicolumn{4}{|c|}{ Time periods post-implementation (Post-policy effects) } \\
\hline \multirow[t]{2}{*}{ 0-1 Year post-policy } & $7.4107^{*}$ & 5.8898 & $-0.0018 *$ & -0.0017 \\
\hline & $(3.9071)$ & $(3.9706)$ & $(0.0010)$ & $(0.0010)$ \\
\hline \multirow[t]{2}{*}{ 1-2 Years post-policy } & $8.4356 * *$ & $6.7607 *$ & -0.0013 & -0.0012 \\
\hline & $(3.8224)$ & (3.9164) & $(0.0008)$ & $(0.0009)$ \\
\hline \multirow[t]{2}{*}{ 2+ Years post-policy } & $11.9377^{* *}$ & $7.2668 *$ & $-0.0019 * *$ & -0.0016 \\
\hline & $(4.5629)$ & $(4.1082)$ & $(0.0009)$ & $(0.0011)$ \\
\hline Year Indicators & Yes & Yes & Yes & Yes \\
\hline Area Fixed Effects & State & County & State & County \\
\hline Observations & $34,655,278$ & $34,655,278$ & $34,673,641$ & $34,673,641$ \\
\hline
\end{tabular}

Notes: All models control for maternal and state covariates listed in Table 3. Standard errors are robust-clustered at the state-level. 
Table 5

Effects of Any Comprehensive Smoking Ban (in at least one venue) on Infant Health Mothers' Education: High school graduate or less

Births 1990-2012

\begin{tabular}{|c|c|c|c|c|c|c|c|c|c|c|}
\hline \multirow[b]{2}{*}{$\begin{array}{l}\text { Model } \\
\text { Outcome }\end{array}$} & \multicolumn{10}{|c|}{ Reference Group: All others } \\
\hline & $\begin{array}{c}\text { (1) } \\
\text { Birthweight }\end{array}$ & $\begin{array}{c}\text { (2) } \\
\text { Low } \\
\text { Birthweight }\end{array}$ & $\begin{array}{c}\text { (3) } \\
\text { Gestation }\end{array}$ & $\begin{array}{c}\text { (4) } \\
\text { Preterm }\end{array}$ & $\begin{array}{c}(5) \\
\text { Fetal } \\
\text { Growth }\end{array}$ & $\begin{array}{c}\text { (6) } \\
\text { Birthweight }\end{array}$ & $\begin{array}{c}\text { (7) } \\
\text { Low } \\
\text { Birthweight }\end{array}$ & $\begin{array}{c}\text { (8) } \\
\text { Gestation }\end{array}$ & $\begin{array}{c}(9) \\
\text { Preterm }\end{array}$ & $\begin{array}{c}(10) \\
\text { Fetal } \\
\text { Growth }\end{array}$ \\
\hline & \multicolumn{10}{|c|}{ Models with State and Year Fixed Effects } \\
\hline $\begin{array}{l}\text { Comprehensive Ban - } \\
\text { Any Venue }\end{array}$ & $\begin{array}{l}8.9571^{* * *} \\
(3.0211)\end{array}$ & $\begin{array}{c}-0.0018^{* *} \\
(0.0008)\end{array}$ & $\begin{array}{l}0.0441^{* *} \\
(0.0176)\end{array}$ & $\begin{array}{l}-0.0011 \\
(0.0013)\end{array}$ & $\begin{array}{c}0.1445^{* * *} \\
(0.0509)\end{array}$ & $\begin{array}{l}7.5172 * * \\
(3.2638)\end{array}$ & $\begin{array}{l}-0.0014 * \\
(0.0008)\end{array}$ & $\begin{array}{l}0.0429 * * \\
(0.0177)\end{array}$ & $\begin{array}{l}-0.0009 \\
(0.0013)\end{array}$ & $\begin{array}{l}0.1100^{*} \\
(0.0582)\end{array}$ \\
\hline Cigarette Tax & $\begin{array}{c}6.6690 * * * \\
(2.0281) \\
\end{array}$ & $\begin{array}{c}-0.0017 * * * \\
(0.0005) \\
\end{array}$ & $\begin{array}{c}0.0336 * * \\
(0.0135) \\
\end{array}$ & $\begin{array}{l}-0.0017^{*} \\
(0.0009) \\
\end{array}$ & $\begin{array}{c}0.1060 * * \\
(0.0420) \\
\end{array}$ & $\begin{array}{c}6.0557 * * * \\
(2.0375)\end{array}$ & $\begin{array}{c}-0.0016 * * * \\
(0.0005) \\
\end{array}$ & $\begin{array}{c}0.0331^{* *} \\
(0.0135) \\
\end{array}$ & $\begin{array}{l}-0.0016^{*} \\
(0.0009)\end{array}$ & $\begin{array}{c}0.0911 * * \\
(0.0408)\end{array}$ \\
\hline & \multicolumn{10}{|c|}{ Models with County and Year Fixed Effects } \\
\hline $\begin{array}{l}\text { Comprehensive Ban - } \\
\text { Any Venue }\end{array}$ & $\begin{array}{l}7.9995 * * \\
(3.3754)\end{array}$ & $\begin{array}{l}-0.0013 \\
(0.0009)\end{array}$ & $\begin{array}{l}0.0424 * * \\
(0.0192)\end{array}$ & $\begin{array}{l}-0.0003 \\
(0.0012)\end{array}$ & $\begin{array}{l}0.1256 * * \\
(0.0563)\end{array}$ & $\begin{array}{l}6.7576^{*} \\
(3.4434)\end{array}$ & $\begin{array}{l}-0.0010 \\
(0.0009)\end{array}$ & $\begin{array}{l}0.0415^{* *} \\
(0.0192)\end{array}$ & $\begin{array}{l}-0.0001 \\
(0.0012)\end{array}$ & $\begin{array}{c}0.0958 \\
(0.0599)\end{array}$ \\
\hline Cigarette Tax & $\begin{array}{c}6.9469 * * * \\
(2.0422)\end{array}$ & $\begin{array}{c}-0.0019 * * * \\
(0.0005) \\
\end{array}$ & $\begin{array}{c}0.0346 * * \\
(0.0135) \\
\end{array}$ & $\begin{array}{c}-0.0020 * * \\
(0.0008) \\
\end{array}$ & $\begin{array}{c}0.1120^{* * *} \\
(0.0412)\end{array}$ & $\begin{array}{c}5.7021^{* * * *} \\
(2.0346) \\
\end{array}$ & $\begin{array}{c}-0.0016 * * * \\
(0.0005) \\
\end{array}$ & $\begin{array}{l}0.0337 * * \\
(0.0135) \\
\end{array}$ & $\begin{array}{c}-0.0019 * * \\
(0.0009) \\
\end{array}$ & $\begin{array}{l}0.0818 * * \\
(0.0397) \\
\end{array}$ \\
\hline $\begin{array}{l}\text { Control for Maternal } \\
\text { Smoking }\end{array}$ & No & No & No & No & No & Yes & Yes & Yes & Yes & Yes \\
\hline Observations & $34,655,278$ & $34,673,641$ & $34,607,278$ & $34,664,996$ & $34,584,285$ & $34,655,278$ & $34,673,641$ & $34,607,278$ & $34,664,996$ & $34,584,285$ \\
\hline
\end{tabular}

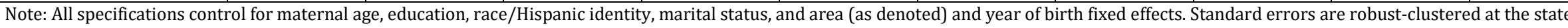

level. Standard errors are clustered at the state level and reported in parentheses. Asterisks denote statistical significance as follows: ${ }^{* * *} \mathrm{p}$-value $\leq 0.01$; ${ }^{* *} 0.01<\mathrm{p}$-value $\leq 0.05$; $* 0.05<\mathrm{p}$-value $\leq 0.10$. 
Table 6

Effects of Comprehensive Smoking Bans in All Venues (Workplace, Restaurants, and Bars) on Child Health, Mothers' Education: High school graduate or less

Children Ages $<18$

NHIS $1998-2013$

\begin{tabular}{|c|c|c|c|c|c|c|c|c|}
\hline \multirow{3}{*}{$\begin{array}{l}\text { Outcome } \\
\text { Hay fever, past year }\end{array}$} & \multicolumn{4}{|c|}{ Panel A: Reference Group - All others } & \multicolumn{4}{|c|}{ Panel B: Reference Group - No bans in any venue } \\
\hline & \multicolumn{2}{|c|}{ State fixed effects } & \multicolumn{2}{|c|}{ County fixed effects } & \multicolumn{2}{|c|}{ State fixed effects } & \multicolumn{2}{|c|}{ County fixed effects } \\
\hline & $\begin{array}{c}0.0127 \\
(0.0079)\end{array}$ & $\begin{array}{c}0.0318 \\
(0.0256)\end{array}$ & $\begin{array}{c}0.0075 \\
(0.0096)\end{array}$ & $\begin{array}{c}0.0215 \\
(0.0274)\end{array}$ & $\begin{array}{c}-0.0125 \\
(0.0145)\end{array}$ & $\begin{array}{c}-0.0396 \\
(0.0451)\end{array}$ & $\begin{array}{c}-0.0001 \\
(0.01578)\end{array}$ & $\begin{array}{c}-0.0219 \\
(0.0498)\end{array}$ \\
\hline Any respiratory allergies, past year & $\begin{array}{c}0.0041 \\
(0.0111)\end{array}$ & $\begin{array}{c}-0.0112 \\
(0.0315)\end{array}$ & $\begin{array}{c}-0.0006 \\
(0.0012)\end{array}$ & $\begin{array}{c}-0.0206 \\
(0.0371)\end{array}$ & $\begin{array}{c}-0.0379 * * \\
(0.0177)\end{array}$ & $\begin{array}{c}-0.1132 * * \\
(0.0434)\end{array}$ & $\begin{array}{c}-0.0176 \\
(0.0190)\end{array}$ & $\begin{array}{c}-0.0539 \\
(0.0563)\end{array}$ \\
\hline Ever diagnosed with asthma & $\begin{array}{c}-0.0000 \\
(0.0081)\end{array}$ & --- & $\begin{array}{c}-0.0062 \\
(0.0090)\end{array}$ & --- & $\begin{array}{c}-0.0125 \\
(0.0164)\end{array}$ & --- & $\begin{array}{c}-0.0120 \\
(0.0161)\end{array}$ & --- \\
\hline Asthma attack, past year & $\begin{array}{c}-0.0088^{*} \\
(0.0051)\end{array}$ & $\begin{array}{c}-0.0556 * * * \\
(0.0163)\end{array}$ & $\begin{array}{c}-0.0127 * * \\
(0.0053)\end{array}$ & $\begin{array}{c}-0.0555^{* *} \\
(0.0225)\end{array}$ & $\begin{array}{c}-0.0173 * * \\
(0.0085)\end{array}$ & $\begin{array}{c}-0.0580 * \\
(0.0322)\end{array}$ & $\begin{array}{c}-0.0181 * \\
(0.0099)\end{array}$ & $\begin{array}{c}-0.0543 \\
(0.0464)\end{array}$ \\
\hline ER visit for asthma, past year & $\begin{array}{c}-0.0005 \\
(0.0020)\end{array}$ & $\begin{array}{c}-0.0023 \\
(0.0198)\end{array}$ & $\begin{array}{c}-0.0009 \\
(0.0027)\end{array}$ & $\begin{array}{c}0.0098 \\
(0.0219)\end{array}$ & $\begin{array}{c}-0.0027 \\
(0.0065)\end{array}$ & $\begin{array}{c}0.0008 \\
(0.0319)\end{array}$ & $\begin{array}{c}-0.0071 \\
(0.0068)\end{array}$ & $\begin{array}{l}-0.0247 \\
(0.0394)\end{array}$ \\
\hline Any ER visit, past year & $\begin{array}{l}-0.0125 \\
(0.0091)\end{array}$ & $\begin{array}{l}-0.0194 \\
(0.0218)\end{array}$ & $\begin{array}{c}-0.0185 * \\
(0.0094)\end{array}$ & $\begin{array}{c}-0.0145 \\
(0.0299)\end{array}$ & $\begin{array}{c}-0.0486 * * * \\
(0.0143)\end{array}$ & $\begin{array}{c}-0.0785 * \\
(0.0459)\end{array}$ & $\begin{array}{c}-0.0521 * * * \\
(0.0122)\end{array}$ & $\begin{array}{l}-0.0866 \\
(0.0621)\end{array}$ \\
\hline $\begin{array}{l}\text { Three or more ear infections, past } \\
\text { year }\end{array}$ & $\begin{array}{l}-0.0010 \\
(0.0052)\end{array}$ & $\begin{array}{c}0.0030 \\
(0.0100)\end{array}$ & $\begin{array}{l}-0.0032 \\
(0.0061)\end{array}$ & $\begin{array}{l}-0.0050 \\
(0.0126)\end{array}$ & $\begin{array}{c}-0.0169 * * \\
(0.0066)\end{array}$ & $\begin{array}{l}-0.0056 \\
(0.0140)\end{array}$ & $\begin{array}{l}-0.0164 * \\
(0.0081)\end{array}$ & $\begin{array}{l}-0.0107 \\
(0.0200)\end{array}$ \\
\hline Excellent or very good general health & $\begin{array}{c}0.0135 \\
(0.0086)\end{array}$ & $\begin{array}{c}0.0070 \\
(0.0261)\end{array}$ & $\begin{array}{c}0.0078 \\
(0.0141)\end{array}$ & $\begin{array}{l}-0.0303 \\
(0.0331)\end{array}$ & $\begin{array}{c}0.0109 \\
(0.0125)\end{array}$ & $\begin{array}{l}-0.0061 \\
(0.0341)\end{array}$ & $\begin{array}{c}0.0226 \\
(0.0174)\end{array}$ & $\begin{array}{c}0.0395 \\
(0.0340)\end{array}$ \\
\hline Fair or poor general health & $\begin{array}{l}-0.0037 \\
(0.0024)\end{array}$ & $\begin{array}{l}-0.0087 \\
(0.0131)\end{array}$ & $\begin{array}{l}-0.0061^{*} \\
(0.0034)\end{array}$ & $\begin{array}{c}0.0116 \\
(0.0205)\end{array}$ & $\begin{array}{l}-0.0070 * \\
(0.0039) \\
\end{array}$ & $\begin{array}{l}-0.0160 \\
(0.0220)\end{array}$ & $\begin{array}{c}-0.0108 * * \\
(0.0052) \\
\end{array}$ & $\begin{array}{l}-0.0244 \\
(0.0189) \\
\end{array}$ \\
\hline Sample & Low educ. & $\begin{array}{l}\text { Asthma } \\
\text { Low educ. }\end{array}$ & Low educ. & $\begin{array}{l}\text { Asthma } \\
\text { Low educ. }\end{array}$ & Low educ. & $\begin{array}{l}\text { Asthma } \\
\text { Low educ. }\end{array}$ & Low educ. & $\begin{array}{l}\text { Asthma } \\
\text { Low educ. }\end{array}$ \\
\hline Observations & 74,193 & 9,674 & 74,193 & 9,674 & 28,370 & 3,894 & 28,370 & 3,894 \\
\hline
\end{tabular}

Note: All specifications control for sex, age, age squared, birthweight, race/ethnicity, mother's education, mother's age, the cigarette excise tax in 2014 dollars, interview year and county fixed effects. Survey

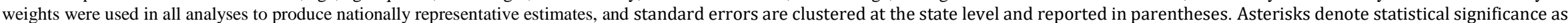
follows: ${ }^{* * *}$-value $\leq 0.01{ }^{* *} 0.01<p$-value $\leq 0.05 ;^{*} 0.05<p$-value $\leq 0.10$. 
Table 7

Effects of Any Comprehensive Smoking Ban (in at least one venue) on Child Health Mothers' Education: High school graduate or less

Children Ages < 18

NHIS 1998 - 2013

\begin{tabular}{|c|c|c|c|c|}
\hline \multirow{3}{*}{$\begin{array}{l}\text { Outcome } \\
\text { Hay fever, past year }\end{array}$} & \multicolumn{4}{|c|}{ Reference Group: All others } \\
\hline & \multicolumn{2}{|c|}{ State fixed effects } & \multicolumn{2}{|c|}{ County fixed effects } \\
\hline & $\begin{array}{c}0.0037 \\
(0.0069)\end{array}$ & $\begin{array}{c}-0.0118 \\
(0.0207)\end{array}$ & $\begin{array}{c}0.0065 \\
(0.0074)\end{array}$ & $\begin{array}{c}0.0172 \\
(0.0196)\end{array}$ \\
\hline Any respiratory allergies, past year & $\begin{array}{c}0.0005 \\
(0.0092)\end{array}$ & $\begin{array}{l}-0.0165 \\
(0.0294)\end{array}$ & $\begin{array}{c}0.0090 \\
(0.0096)\end{array}$ & $\begin{array}{l}-0.0012 \\
(0.0303)\end{array}$ \\
\hline Ever diagnosed with asthma & $\begin{array}{c}0.0037 \\
(0.0071)\end{array}$ & --- & $\begin{array}{c}0.0032 \\
(0.0066)\end{array}$ & --- \\
\hline Asthma attack, past year & $\begin{array}{l}-0.0023 \\
(0.0035)\end{array}$ & $\begin{array}{l}-0.0181 \\
(0.0169)\end{array}$ & $\begin{array}{l}-0.0029 \\
(0.0039)\end{array}$ & $\begin{array}{l}-0.0129 \\
(0.0228)\end{array}$ \\
\hline ER visit for asthma, past year & $\begin{array}{c}0.0006 \\
(0.0024)\end{array}$ & $\begin{array}{c}0.0022 \\
(0.0142)\end{array}$ & $\begin{array}{c}0.0000 \\
(0.0024)\end{array}$ & $\begin{array}{c}0.0073 \\
(0.0162)\end{array}$ \\
\hline Any ER visit, past year & $\begin{array}{c}-0.0171^{* *} \\
(0.0076)\end{array}$ & $\begin{array}{l}-0.0126 \\
(0.0287)\end{array}$ & $\begin{array}{l}-0.0027 \\
(0.0090)\end{array}$ & $\begin{array}{c}0.0163 \\
(0.0296)\end{array}$ \\
\hline Three or more ear infections, past year & $\begin{array}{c}0.0049 \\
(0.0051)\end{array}$ & $\begin{array}{c}0.0135 \\
(0.0132)\end{array}$ & $\begin{array}{c}0.0077 \\
(0.0053)\end{array}$ & $\begin{array}{l}-0.0018 \\
(0.0166)\end{array}$ \\
\hline Excellent or very good general health & $\begin{array}{c}0.0000 \\
(0.0081)\end{array}$ & $\begin{array}{l}-0.0309 \\
(0.0238)\end{array}$ & $\begin{array}{c}0.0001 \\
(0.0093)\end{array}$ & $\begin{array}{l}-0.0391 \\
(0.0271)\end{array}$ \\
\hline Fair or poor general health & $\begin{array}{l}-0.0014 \\
(0.0026) \\
\end{array}$ & $\begin{array}{l}-0.0092 \\
(0.0157) \\
\end{array}$ & $\begin{array}{l}-0.0028 \\
(0.0028) \\
\end{array}$ & $\begin{array}{c}0.0058 \\
(0.0165) \\
\end{array}$ \\
\hline Sample & Low educ. & $\begin{array}{c}\text { Asthma } \\
\text { Low educ. }\end{array}$ & Low educ. & $\begin{array}{l}\text { Asthma } \\
\text { Low educ. }\end{array}$ \\
\hline Observations & 74,193 & 9,674 & 74,193 & 9,674 \\
\hline
\end{tabular}




\section{Table 8}

Effects of Comprehensive Smoking Bans in All Venues (Workplace, Restaurants, and Bars)

on Smoking At Home

Adult Education: High school graduate or less

Households with children (ages < 18)

NHIS 1998 - 2010

\begin{tabular}{|c|c|c|c|c|c|c|}
\hline Outcome & \multicolumn{6}{|c|}{ Smoking inside the home on one or more days per week } \\
\hline Panel A & \multicolumn{6}{|c|}{ Reference Group: All others } \\
\hline \multirow{2}{*}{ Sample } & \multicolumn{3}{|c|}{ State fixed effects } & \multicolumn{3}{|c|}{ County fixed effects } \\
\hline & All & $\begin{array}{l}\text { Current } \\
\text { smokers }\end{array}$ & $\begin{array}{c}\text { Current and } \\
\text { former smokers }\end{array}$ & All & $\begin{array}{l}\text { Current } \\
\text { smokers }\end{array}$ & $\begin{array}{c}\begin{array}{c}\text { Current and } \\
\text { former smokers }\end{array} \\
\end{array}$ \\
\hline Model & (1) & (2) & (3) & (4) & (5) & (6) \\
\hline $\begin{array}{l}\text { Comprehensive Ban - } \\
\text { All Venues }\end{array}$ & $\begin{array}{l}-0.0005 \\
(0.0114)\end{array}$ & $\begin{array}{l}-0.05289 \\
(0.0318)\end{array}$ & $\begin{array}{l}-0.0246 \\
(0.0187)\end{array}$ & $\begin{array}{l}-0.0175 \\
(0.0185)\end{array}$ & $\begin{array}{l}-0.0887 \\
(0.0571)\end{array}$ & $\begin{array}{l}-0.0293 \\
(0.0333)\end{array}$ \\
\hline Cigarette Tax & $\begin{array}{l}-0.0228 * \\
(0.0117)\end{array}$ & $\begin{array}{c}0.0013 \\
(0.0249)\end{array}$ & $\begin{array}{l}-0.0114 \\
(0.0168)\end{array}$ & $\begin{array}{l}-0.0159 \\
(0.0120)\end{array}$ & $\begin{array}{c}0.0055 \\
(0.0288)\end{array}$ & $\begin{array}{l}-0.0056 \\
(0.0207)\end{array}$ \\
\hline Outcome & \multicolumn{6}{|c|}{ Smoking inside the home on one or more days per week } \\
\hline Panel B & \multicolumn{6}{|c|}{ Reference Group: No bans in any venue } \\
\hline \multirow{2}{*}{ Sample } & \multicolumn{3}{|c|}{ State fixed effects } & \multicolumn{3}{|c|}{ County fixed effects } \\
\hline & All & $\begin{array}{l}\text { Current } \\
\text { smokers }\end{array}$ & $\begin{array}{c}\text { Current and } \\
\text { former smokers }\end{array}$ & All & $\begin{array}{l}\text { Current } \\
\text { smokers }\end{array}$ & $\begin{array}{c}\text { Current and } \\
\text { former smokers }\end{array}$ \\
\hline Model & (1) & (2) & (3) & (4) & (5) & (6) \\
\hline $\begin{array}{l}\text { Comprehensive Ban - } \\
\text { All Venues }\end{array}$ & $\begin{array}{l}-0.0163 \\
(0.0242)\end{array}$ & $\begin{array}{c}-0.1127 * * * \\
(0.0301)\end{array}$ & $\begin{array}{l}-0.0191 \\
(0.0285)\end{array}$ & $\begin{array}{l}-0.0480 \\
(0.0299)\end{array}$ & $\begin{array}{c}-0.2235 * * * \\
(0.0387)\end{array}$ & $\begin{array}{l}-0.0589 * \\
(0.0301)\end{array}$ \\
\hline
\end{tabular}




\section{Appendix Table 1}

Effects of Comprehensive Smoking Bans in All Venues (Workplace, Restaurants, and Bars) on Infant Health

Full Sample

Births 1990-2012

\begin{tabular}{|c|c|c|c|c|c|c|c|c|c|c|}
\hline Panel A & \multicolumn{10}{|c|}{ Reference Group: All others } \\
\hline $\begin{array}{l}\text { Model } \\
\text { Outcome }\end{array}$ & $\begin{array}{c}\text { (1) } \\
\text { Birthweight }\end{array}$ & $\begin{array}{c}(2) \\
\text { Low } \\
\text { Birthweight }\end{array}$ & $\begin{array}{c}\text { (3) } \\
\text { Gestation }\end{array}$ & $\begin{array}{c}\text { (4) } \\
\text { Preterm }\end{array}$ & $\begin{array}{c}(5) \\
\text { Fetal } \\
\text { Growth }\end{array}$ & $\begin{array}{c}\text { (6) } \\
\text { Birthweight }\end{array}$ & $\begin{array}{c}(7) \\
\text { Low } \\
\text { Birthweight }\end{array}$ & $\begin{array}{c}\text { (8) } \\
\text { Gestation }\end{array}$ & $\begin{array}{c}\text { (9) } \\
\text { Preterm }\end{array}$ & $\begin{array}{c}(10) \\
\text { Fetal } \\
\text { Growth }\end{array}$ \\
\hline & \multicolumn{10}{|c|}{ Models with State and Year Fixed Effects } \\
\hline $\begin{array}{l}\text { Comprehensive Ban - All Venues } \\
\text { Cigarette Tax }\end{array}$ & $\begin{array}{l}7.9224^{*} \\
(4.1813) \\
3.4521^{* *} \\
(1.5899) \\
\end{array}$ & $\begin{array}{c}-0.0012 * * \\
(0.0006) \\
-0.0008 * * \\
(0.0003) \\
\end{array}$ & $\begin{array}{c}0.0417^{* *} \\
(0.0195) \\
0.0238^{* *} \\
(0.0113) \\
\end{array}$ & $\begin{array}{c}0.0001 \\
(0.0012) \\
-0.0012 \\
(0.0007) \\
\end{array}$ & \begin{tabular}{|c|}
$0.1222^{*}$ \\
$(0.0731)$ \\
0.0422 \\
$(0.0332)$ \\
\end{tabular} & $\begin{array}{l}7.3850^{*} \\
(4.3802) \\
3.0982^{*} \\
(1.6139) \\
\end{array}$ & $\begin{array}{c}-0.0011^{*} \\
(0.0006) \\
-0.0007^{* *} \\
(0.0004) \\
\end{array}$ & $\begin{array}{l}0.0413^{* *} \\
(0.0194) \\
0.0235^{* *} \\
(0.0113) \\
\end{array}$ & $\begin{array}{c}0.0001 \\
(0.0013) \\
-0.0011 \\
(0.0008) \\
\end{array}$ & $\begin{array}{c}0.1093 \\
(0.0804) \\
0.0336 \\
(0.0326) \\
\end{array}$ \\
\hline & \multicolumn{10}{|c|}{ Models with County and Year Fixed Effects } \\
\hline $\begin{array}{l}\text { Comprehensive Ban - All Venues } \\
\text { Cigarette Tax }\end{array}$ & $\begin{array}{c}3.4512 \\
(3.2152) \\
3.9244^{* *} \\
(1.6823) \\
\end{array}$ & $\begin{array}{c}-.0009 \\
(.0007) \\
-.0010^{* * *} \\
(.0003) \\
\end{array}$ & $\begin{array}{l}0.0264 \\
(0.0188) \\
.0266^{* *} \\
(.0110) \\
\end{array}$ & $\begin{array}{c}0.0012 \\
(0.0010) \\
-.0015^{* *} \\
(.0007) \\
\end{array}$ & $\begin{array}{c}0.0470 \\
(0.0579) \\
.0487 \\
(.0353) \\
\end{array}$ & $\begin{array}{c}2.5381 \\
(3.1705) \\
3.2746^{*} \\
(1.6763) \\
\end{array}$ & $\begin{array}{c}-.0007 \\
(.0007) \\
-.0009 * * \\
(.0004) \\
\end{array}$ & $\begin{array}{l}0.0257 \\
(0.0186) \\
.0261 * * \\
(.0111) \\
\end{array}$ & $\begin{array}{l}0.0013 \\
(0.0010) \\
-.0014 * \\
(.0007) \\
\end{array}$ & $\begin{array}{c}0.0251 \\
(0.0601) \\
.0353 \\
(.0339) \\
\end{array}$ \\
\hline Control for Maternal Smoking & No & No & No & No & No & Yes & Yes & Yes & Yes & Yes \\
\hline Observations & $69,053,313$ & $69,085,073$ & $68,986,569$ & $69,074,498$ & $68,944,881$ & $69,053,313$ & $69,085,073$ & $68,986,569$ & $69,074,498$ & $68,944,881$ \\
\hline Panel B & \multicolumn{10}{|c|}{ Reference Group: No bans in any venue } \\
\hline $\begin{array}{l}\text { Model } \\
\text { Outcome }\end{array}$ & $\begin{array}{c}(1) \\
\text { Birthweight } \\
\end{array}$ & $\begin{array}{c}\text { (2) } \\
\text { Low } \\
\text { Birthweight }\end{array}$ & $\begin{array}{c}\text { (3) } \\
\text { Gestation }\end{array}$ & $\begin{array}{c}(4) \\
\text { Preterm } \\
\end{array}$ & $\begin{array}{c}5) \\
\text { Fetal } \\
\text { Growth }\end{array}$ & $\begin{array}{c}\text { (6) } \\
\text { Birthweight } \\
\end{array}$ & $\begin{array}{c}\text { (7) } \\
\text { Low } \\
\text { Birthweight } \\
\end{array}$ & $\begin{array}{c}(8) \\
\text { Gestation } \\
\end{array}$ & $\begin{array}{c}(9) \\
\text { Preterm } \\
\end{array}$ & $\begin{array}{c}(10) \\
\text { Fetal } \\
\text { Growth } \\
\end{array}$ \\
\hline & \multicolumn{10}{|c|}{ Models with State and Year Fixed Effects } \\
\hline $\begin{array}{l}\text { Comprehensive Ban - All Venues } \\
\text { Cigarette Tax }\end{array}$ & $\begin{array}{l}12.8299^{*} \\
(6.5769) \\
2.8696 * * \\
(1.3469)\end{array}$ & $\begin{array}{c}-0.0020 \\
(0.0015) \\
-0.0009 * * \\
(0.0004)\end{array}$ & $\begin{array}{c}0.0663^{*} \\
(0.0369) \\
0.0318 * * \\
(0.0153)\end{array}$ & $\begin{array}{l}-0.0003 \\
(0.0019) \\
-0.0013 \\
(0.0008)\end{array}$ & $\begin{array}{c}0.2064^{*} \\
(0.1071) \\
0.0131 \\
(0.0228)\end{array}$ & $\begin{array}{c}11.1824^{*} \\
(6.4289) \\
2.7685 \\
(1.7643)\end{array}$ & $\begin{array}{l}-0.0016 \\
(0.0015) \\
-0.0008^{*} \\
(0.0005)\end{array}$ & $\begin{array}{l}0.0650^{*} \\
(0.0364) \\
0.0317^{* *} \\
(0.0154)\end{array}$ & $\begin{array}{l}-0.0001 \\
(0.0018) \\
-0.0013 \\
(0.0009)\end{array}$ & $\begin{array}{c}0.1667 \\
(0.1132) \\
0.0108 \\
(0.0307)\end{array}$ \\
\hline & \multicolumn{10}{|c|}{ Models with County and Year Fixed Effects } \\
\hline $\begin{array}{l}\text { Comprehensive Ban - All Venues } \\
\text { Cigarette Tax }\end{array}$ & $\begin{array}{c}7.9000 \\
(5.3589) \\
3.3148 * * \\
(1.3573) \\
\end{array}$ & $\begin{array}{c}-0.0013 \\
(0.0014) \\
-.0012^{* * *} \\
(.0004) \\
\end{array}$ & $\begin{array}{l}0.0598 * * \\
(0.0293) \\
.0379 * * \\
(.0143) \\
\end{array}$ & $\begin{array}{c}0.0005 \\
(0.0016) \\
-.0018^{* *} \\
.0008 \\
\end{array}$ & $\begin{array}{c}0.0996 \\
(0.0864) \\
.0138 \\
(.0202) \\
\end{array}$ & $\begin{array}{c}6.2665 \\
(5.3750) \\
2.4479 \\
(1.6543) \\
\end{array}$ & $\begin{array}{l}-0.0010 \\
(0.0014) \\
-.0010 * \\
.0005 \\
\end{array}$ & $\begin{array}{l}0.0586^{*} \\
(0.0292) \\
.0372 * * \\
(.0145) \\
\end{array}$ & $\begin{array}{c}0.0007 \\
(0.0016) \\
-.0017 * \\
(.0009) \\
\end{array}$ & $\begin{array}{c}0.0601 \\
(0.0894) \\
-.0071 \\
(.0223) \\
\end{array}$ \\
\hline Control for Maternal Smoking & No & No & No & No & No & Yes & Yes & Yes & Yes & Yes \\
\hline Observations & $35,404,894$ & $35,422,066$ & $35,366,122$ & $35,418,015$ & $35,346,196$ & $35,404,894$ & $35,422,066$ & $35,366,122$ & $35,418,015$ & $35,346,196$ \\
\hline
\end{tabular}


Appendix Table 2

Effects of Comprehensive Smoking Bans in All Venues (Workplace, Restaurants, and Bars) on Child Health Children Ages < 18, Full Sample

NHIS 1998 - 2013

\begin{tabular}{|c|c|c|c|c|c|c|c|c|}
\hline \multirow{3}{*}{$\begin{array}{l}\text { Outcome } \\
\text { Hay fever, past year }\end{array}$} & \multicolumn{4}{|c|}{ Panel A: Reference Group All others } & \multicolumn{4}{|c|}{ Panel B: Reference Group No Bans } \\
\hline & \multicolumn{2}{|c|}{ State fixed effects } & \multicolumn{2}{|c|}{ County fixed effects } & \multicolumn{2}{|c|}{ State fixed effects } & \multicolumn{2}{|c|}{ County fixed effects } \\
\hline & $\begin{array}{l}-0.0043 \\
(0.0060)\end{array}$ & $\begin{array}{c}0.0021 \\
(0.0173)\end{array}$ & $\begin{array}{l}-0.0012 \\
(0.0045)\end{array}$ & $\begin{array}{l}-0.0002 \\
(0.0166)\end{array}$ & $\begin{array}{l}-0.0104 \\
(0.0084)\end{array}$ & $\begin{array}{l}-0.0180 \\
(0.0220)\end{array}$ & $\begin{array}{c}0.0027 \\
(0.0098)\end{array}$ & $\begin{array}{c}-0.0041 \\
(0.0278)\end{array}$ \\
\hline Any respiratory allergies, past year & $\begin{array}{c}-0.0195 * * * \\
(0.0063)\end{array}$ & $\begin{array}{c}-0.0472 * * * \\
(0.0153)\end{array}$ & $\begin{array}{c}-0.0113 * * \\
(0.0048)\end{array}$ & $\begin{array}{c}-0.0395 * * \\
(0.0162)\end{array}$ & $\begin{array}{c}-0.0444 * * * \\
(0.0139)\end{array}$ & $\begin{array}{c}-0.0877 * * * \\
(0.0264)\end{array}$ & $\begin{array}{l}-0.0076 \\
(0.0135)\end{array}$ & $\begin{array}{l}-0.0195 \\
(0.0313)\end{array}$ \\
\hline Ever diagnosed with asthma & $\begin{array}{l}-0.0067 \\
(0.0048)\end{array}$ & --- & $\begin{array}{l}-0.0079 * \\
(0.0045)\end{array}$ & --- & $\begin{array}{l}-0.0087 \\
(0.0074)\end{array}$ & --- & $\begin{array}{l}-0.0104 \\
(0.0086)\end{array}$ & --- \\
\hline Asthma attack, past year & $\begin{array}{c}-0.0108 * * * \\
(0.0026)\end{array}$ & $\begin{array}{c}-0.0564 * * * \\
(0.0113)\end{array}$ & $\begin{array}{c}-0.0103 * * * \\
(0.0031)\end{array}$ & $\begin{array}{c}0.0480 * * * \\
(0.0177)\end{array}$ & $\begin{array}{c}-0.01594^{* *} \\
(0.0061)\end{array}$ & $\begin{array}{c}-0.0797 * * * \\
(0.0247)\end{array}$ & $\begin{array}{l}-0.0115^{*} \\
(0.0064)\end{array}$ & $\begin{array}{l}-0.0332 \\
(0.0279)\end{array}$ \\
\hline ER visit for asthma, past year & $\begin{array}{c}-0.0028 * * \\
(0.0012)\end{array}$ & $\begin{array}{c}-0.0154^{* *} \\
(0.0072)\end{array}$ & $\begin{array}{l}-0.0024 \\
(0.0015)\end{array}$ & $\begin{array}{l}-0.0085 \\
(0.0124)\end{array}$ & $\begin{array}{c}-0.0065^{* * *} \\
(0.0023)\end{array}$ & $\begin{array}{c}-0.0366^{* * *} \\
(0.0128)\end{array}$ & $\begin{array}{c}-0.0063^{* *} \\
(0.0029)\end{array}$ & $\begin{array}{l}-0.0294 \\
(0.0177)\end{array}$ \\
\hline Any ER visit, past year & $\begin{array}{l}-0.0050 \\
(0.0064)\end{array}$ & $\begin{array}{c}-0.0265^{* *} \\
(0.0126)\end{array}$ & $\begin{array}{l}-0.0034 \\
(0.0059)\end{array}$ & $\begin{array}{l}-0.0222 \\
(0.0196)\end{array}$ & $\begin{array}{l}-0.0175^{*} \\
(0.0088)\end{array}$ & $\begin{array}{c}-0.0705^{* * *} \\
(0.0159)\end{array}$ & $\begin{array}{l}-0.0139 \\
(0.0091)\end{array}$ & $\begin{array}{l}-0.0592 * \\
(0.0303)\end{array}$ \\
\hline Three or more ear infections, past year & $\begin{array}{l}-0.0045 \\
(0.0031)\end{array}$ & $\begin{array}{l}-0.0151 * \\
(0.0077)\end{array}$ & $\begin{array}{l}-0.0028 \\
(0.0034)\end{array}$ & $\begin{array}{l}-0.0048 \\
(0.0086)\end{array}$ & $\begin{array}{c}-0.0114 * * * \\
(0.0036)\end{array}$ & $\begin{array}{c}-0.0260^{* *} \\
(0.0114)\end{array}$ & $\begin{array}{l}-0.0069 \\
(0.0042)\end{array}$ & $\begin{array}{l}-0.0038 \\
(0.0173)\end{array}$ \\
\hline Excellent or very good general health & $\begin{array}{c}0.0041 \\
(0.0057)\end{array}$ & $\begin{array}{c}0.0111 \\
(0.0149)\end{array}$ & $\begin{array}{c}0.0040 \\
(0.0074)\end{array}$ & $\begin{array}{c}0.0032 \\
(0.0182)\end{array}$ & $\begin{array}{c}0.0114 \\
(0.0086)\end{array}$ & $\begin{array}{l}0.0362 * \\
(0.0195)\end{array}$ & $\begin{array}{c}0.0082 \\
(0.0093)\end{array}$ & $\begin{array}{c}0.0270 \\
(0.0232)\end{array}$ \\
\hline Fair or poor general health & $\begin{array}{l}-0.0006 \\
(0.0013)\end{array}$ & $\begin{array}{l}-0.0059 \\
(0.0064) \\
\end{array}$ & $\begin{array}{l}-0.0024 \\
(0.0019) \\
\end{array}$ & $\begin{array}{c}0.0001 \\
(0.0090) \\
\end{array}$ & $\begin{array}{c}-0.0058 * * * \\
(0.0018) \\
\end{array}$ & $\begin{array}{c}-0.0228 * * * \\
(0.0082) \\
\end{array}$ & $\begin{array}{c}-0.0058 * * \\
(0.0028) \\
\end{array}$ & $\begin{array}{c}-0.0227 * * \\
(0.0101) \\
\end{array}$ \\
\hline Sample & All children & Asthma & All children & Asthma & All children & Asthma & All children & Asthma \\
\hline Observations & 167,328 & 22,157 & 167,328 & 22,157 & 63,535 & 8,645 & 63,535 & 8,645 \\
\hline
\end{tabular}

Note: All specifications control for sex, age, age squared, birthweight, race/ethnicity, mother's education, mother's age, the cigarette excise tax in 2014 dollars, interview year and county fixed effects. Survey weights were used in all analyses to produce nationally representative estimates, and standard errors are clustered at the state level and reported in parentheses. Asterisks denote statistical significance as follows: ${ }^{* *}$ p-value $\leq 0.01 ; * * 0.01<$ p-value $\leq 0.05 ; * 0.05<$-value $\leq 0.10$. 


\section{Appendix Table 3}

Effects of Comprehensive Smoking Bans in All Venues (Workplace, Restaurants, and Bars) on Infant Health

Differential Effects by Urban and Rural Residence

Mothers' Education Level: High school graduate or less

Births 1990 - 2012

Reference Group: All Others

\begin{tabular}{|c|c|c|c|c|c|c|c|c|}
\hline Reference: All Others & $\begin{array}{c}\text { (1) } \\
\text { Birthweight }\end{array}$ & $\begin{array}{c}\text { (2) } \\
\text { Low } \\
\text { Birthweight }\end{array}$ & $\begin{array}{c}\text { (3) } \\
\text { Birthweight }\end{array}$ & $\begin{array}{c}\text { (4) } \\
\text { Low } \\
\text { Birthweight }\end{array}$ & $\begin{array}{c}\text { (5) } \\
\text { Birthweight }\end{array}$ & $\begin{array}{c}\text { (6) } \\
\text { Low } \\
\text { Birthweight }\end{array}$ & $\begin{array}{c}\text { (7) } \\
\text { Birthweight }\end{array}$ & $\begin{array}{c}\text { (8) } \\
\text { Low } \\
\text { Birthweight }\end{array}$ \\
\hline Comprehensive Ban - All Venues & $\begin{array}{l}9.0262^{* *} \\
(3.5319)\end{array}$ & $\begin{array}{l}-0.0025 * * * \\
(0.0008)\end{array}$ & $\begin{array}{c}5.6531 \\
(4.3360)\end{array}$ & $\begin{array}{c}-0.0017 * * * \\
(0.0006)\end{array}$ & $\begin{array}{l}9.6130 * * \\
(3.6854)\end{array}$ & $\begin{array}{c}-0.0028 * * * \\
(0.0010)\end{array}$ & $\begin{array}{l}6.7171^{*} \\
(3.8657)\end{array}$ & $\begin{array}{l}-0.0021^{* *} \\
(0.0009)\end{array}$ \\
\hline Medium Metropolitan & $\begin{array}{l}-11.5004^{*} \\
(6.6151)\end{array}$ & $\begin{array}{l}0.0022 * * \\
(0.0009)\end{array}$ & $\begin{array}{l}-5.7667 \\
(6.6629)\end{array}$ & $\begin{array}{c}0.0009 \\
(0.0009)\end{array}$ & - & - & - & - \\
\hline Non-Metropolitan & $\begin{array}{c}-14.2320^{* *} \\
(6.0931)\end{array}$ & $\begin{array}{l}0.0021^{* *} \\
(0.0010)\end{array}$ & $\begin{array}{l}-5.5538 \\
(6.2044)\end{array}$ & $\begin{array}{c}0.0001 \\
(0.0009)\end{array}$ & - & - & - & - \\
\hline $\begin{array}{l}\text { Comprehensive Ban* } \\
\text { Medium Metropolitan }\end{array}$ & $\begin{array}{c}8.9309 \\
(7.0146)\end{array}$ & $\begin{array}{c}0.0007 \\
(0.0017)\end{array}$ & $\begin{array}{l}14.7693 * \\
(8.2092)\end{array}$ & $\begin{array}{l}-0.0007 \\
(0.0012)\end{array}$ & $\begin{array}{c}-6.7212 * * \\
(3.0495)\end{array}$ & $\begin{array}{l}0.0031 * * * \\
(0.0008)\end{array}$ & $\begin{array}{l}-4.8181 * \\
(2.7816)\end{array}$ & $\begin{array}{c}0.0027 * * * \\
(0.0008)\end{array}$ \\
\hline Comprehensive Ban* & 1.1285 & 0.0024 & 12.0556 & -0.0002 & $-11.4315 * * *$ & $0.0042 * * *$ & $-3.3288^{*}$ & $0.0024 * *$ \\
\hline Non-Metropolitan & $(5.1481)$ & $(0.0015)$ & $(8.1344)$ & $(0.0010)$ & $(2.0807)$ & $(0.0009)$ & $(1.8548)$ & $(0.0009)$ \\
\hline Other controls from main spec. & Yes & Yes & Yes & Yes & Yes & Yes & Yes & Yes \\
\hline Maternal Smoking & No & No & Yes & Yes & No & No & Yes & Yes \\
\hline Fixed Effects & State & State & State & State & County & County & County & County \\
\hline Year Fixed Effects & Yes & Yes & Yes & Yes & Yes & Yes & Yes & Yes \\
\hline Observations & $34,655,278$ & $34,673,641$ & $34,655,278$ & $34,673,641$ & $34,655,278$ & $34,673,641$ & $34,655,278$ & $34,673,641$ \\
\hline
\end{tabular}

Note: The reference category, "Large Metropolitan" corresponds to codes 1 and 2 of the NCHS 2013 Urban-Rural Classification Scheme (MSA above 1 million). "Medium Metropolitan" corresponds to codes 3 and 4 (Metropolitan area below 1 million), and "Non-Metropolitan" corresponds to codes 5 and 6 (area population below 50,000) 


\section{Appendix Table 4}

Effects of Comprehensive Smoking Bans in All Venues (Workplace, Restaurants, and Bars) on Infant Health

Differential Effects by Urban and Rural Residence

Mothers' Education Level: High school graduate or less

Births $1990-2012$

Reference Group: No Bans in any Venue

\begin{tabular}{|c|c|c|c|c|c|c|c|c|}
\hline Reference: All Others & $\begin{array}{c}\text { (1) } \\
\text { Birthweight }\end{array}$ & $\begin{array}{c}\text { (2) } \\
\text { Low } \\
\text { Birthweight }\end{array}$ & $\begin{array}{c}\text { (3) } \\
\text { Birthweight }\end{array}$ & $\begin{array}{c}\text { (4) } \\
\text { Low } \\
\text { Birthweight }\end{array}$ & $\begin{array}{c}\text { (5) } \\
\text { Birthweight }\end{array}$ & $\begin{array}{c}\text { (6) } \\
\text { Low } \\
\text { Birthweight }\end{array}$ & $\begin{array}{c}\text { (7) } \\
\text { Birthweight }\end{array}$ & $\begin{array}{c}\text { (8) } \\
\text { Low } \\
\text { Birthweight }\end{array}$ \\
\hline Comprehensive Ban - All Venues & $\begin{array}{c}13.4808^{* *} \\
(5.8740)\end{array}$ & $\begin{array}{l}-0.0032^{*} \\
(0.0017)\end{array}$ & $\begin{array}{l}9.9774^{*} \\
(5.7880)\end{array}$ & $\begin{array}{l}-0.0023 \\
(0.0017)\end{array}$ & $\begin{array}{c}17.3177^{* *} \\
(6.5255)\end{array}$ & $\begin{array}{c}-0.0040^{* *} \\
(0.0019)\end{array}$ & $\begin{array}{c}13.6930^{* *} \\
(6.7651)\end{array}$ & $\begin{array}{l}-0.0032^{*} \\
(0.0019)\end{array}$ \\
\hline Medium Metropolitan & $\begin{array}{c}-13.4275^{* *} \\
(6.3534)\end{array}$ & $\begin{array}{c}0.0022 * * * \\
(0.0007)\end{array}$ & $\begin{array}{l}-6.9384 \\
(7.2358)\end{array}$ & $\begin{array}{c}0.0007 \\
(0.0008)\end{array}$ & - & - & - & - \\
\hline Non-Metropolitan & $\begin{array}{c}-17.3610^{* * * *} \\
(5.9828)\end{array}$ & $\begin{array}{c}0.0024 * * \\
(0.0010)\end{array}$ & $\begin{array}{l}-9.3650 \\
(6.0970)\end{array}$ & $\begin{array}{c}0.0006 \\
(0.0009)\end{array}$ & - & - & - & - \\
\hline Comprehensive Ban* & 9.9309 & 0.0006 & $15.2852 *$ & -0.0006 & $-10.6073 * *$ & $0.0041^{* * *}$ & $-9.3001 * * *$ & $0.0038 * * *$ \\
\hline $\begin{array}{l}\text { Medium Metropolitan } \\
\text { Comprehensive Ban* }\end{array}$ & $\begin{array}{c}(7.5004) \\
7.0821\end{array}$ & $\begin{array}{c}(0.0017) \\
0.0014\end{array}$ & $\begin{array}{c}(8.4358) \\
19.1834 * *\end{array}$ & $\begin{array}{l}(0.0011) \\
-0.0014\end{array}$ & $-17.1183^{* * *}$ & $0.0052 * * *$ & $-7.2347 * * *$ & $0.0029 * *$ \\
\hline Non-Metropolitan & $(5.1976)$ & $(0.0015)$ & $(7.7406)$ & $(0.0009)$ & (3.1858) & $(0.0012)$ & $(2.6241)$ & $(0.0011)$ \\
\hline Other controls from main spec. & Yes & Yes & Yes & Yes & Yes & Yes & Yes & Yes \\
\hline Maternal Smoking & No & No & Yes & Yes & No & No & Yes & Yes \\
\hline Fixed Effects & State & State & State & State & County & County & County & County \\
\hline Year Fixed Effects & Yes & Yes & Yes & Yes & Yes & Yes & Yes & Yes \\
\hline Observations & $18,156,650$ & $18,166,551$ & $18,156,650$ & $18,166,551$ & $18,156,650$ & $18,156,551$ & $18,156,650$ & $18,156,551$ \\
\hline
\end{tabular}

Note: The reference category, "Large Metropolitan" corresponds to codes 1 and 2 of the NCHS 2013 Urban-Rural Classification Scheme (MSA above 1 million). "Medium

Metropolitan" corresponds to codes 3 and 4 (Metropolitan area below 1 million), and "Non-Metropolitan" corresponds to codes 5 and 6 (area population below 50,000) 


\section{Appendix Table 5}

Effects of Comprehensive Smoking Bans in All Venues (Workplace, Restaurants, and Bars) on Infant Health Mothers' Education Level: High school graduate or less

\section{Results Using 1995-2009 Sample of Births}

(Gao and Baughman 2017)

Reference Group: All Others

\begin{tabular}{|c|c|c|c|c|c|c|c|c|}
\hline Reference Group: All other & $\begin{array}{c}\text { (1) } \\
\text { Birthweight }\end{array}$ & $\begin{array}{c}\text { (2) } \\
\text { Low } \\
\text { Birthweight }\end{array}$ & $\begin{array}{c}\text { (3) } \\
\text { Birthweight }\end{array}$ & $\begin{array}{c}\text { (4) } \\
\text { Low } \\
\text { Birthweight }\end{array}$ & $\begin{array}{c}\text { (5) } \\
\text { Birthweight }\end{array}$ & $\begin{array}{c}\text { (6) } \\
\text { Low } \\
\text { Birthweight }\end{array}$ & $\begin{array}{c}\text { (7) } \\
\text { Birthweight }\end{array}$ & $\begin{array}{c}\text { (8) } \\
\text { Low } \\
\text { Birthweight }\end{array}$ \\
\hline Comprehensive Ban - All Venues & $\begin{array}{c}12.1025^{* * *} \\
(4.3736)\end{array}$ & $\begin{array}{c}-0.0021^{* * *} \\
(0.0007)\end{array}$ & $\begin{array}{c}11.1675^{* *} \\
(4.8263)\end{array}$ & $\begin{array}{c}-0.0018^{* *} \\
(0.0008)\end{array}$ & $\begin{array}{c}7.6775^{* *} \\
(3.3479)\end{array}$ & $\begin{array}{c}-0.0017^{* *} \\
(0.0008)\end{array}$ & $\begin{array}{c}5.7312 \\
(3.4734)\end{array}$ & $\begin{array}{l}-0.0012 \\
(0.0008)\end{array}$ \\
\hline Mother's Age & $\begin{array}{c}2.9723 * * * \\
(0.3504)\end{array}$ & $\begin{array}{c}0.0010^{* * *} \\
(0.0001)\end{array}$ & $\begin{array}{c}3.1339 * * * \\
(0.3194)\end{array}$ & $\begin{array}{c}0.0009 * * * \\
(0.0001)\end{array}$ & $\begin{array}{c}2.8166 * * * \\
(0.3318)\end{array}$ & $\begin{array}{c}0.0010^{* * * *} \\
(0.0001)\end{array}$ & $\begin{array}{c}3.1039 * * * \\
(0.2916)\end{array}$ & $\begin{array}{c}0.0010 * * * \\
(0.0001)\end{array}$ \\
\hline Mother's Education & $\begin{array}{c}3.9997 * * \\
(1.6468)\end{array}$ & $\begin{array}{c}-0.0009 * * * \\
(0.0003)\end{array}$ & $\begin{array}{c}1.6690 \\
(1.3630)\end{array}$ & $\begin{array}{l}-0.0004 \\
(0.0002)\end{array}$ & $\begin{array}{c}4.6836 * * * \\
(1.3475)\end{array}$ & $\begin{array}{c}-0.0010^{* * *} \\
(0.0003)\end{array}$ & $\begin{array}{c}2.1979 * * \\
(1.0210)\end{array}$ & $\begin{array}{c}-0.0005^{* *} \\
(0.0002)\end{array}$ \\
\hline Black & $\begin{array}{c}-175.9045^{* * *} \\
(5.7330)\end{array}$ & $\begin{array}{c}0.0466 * * * \\
(0.0016)\end{array}$ & $\begin{array}{c}-211.9432 * * * \\
(6.6917)\end{array}$ & $\begin{array}{c}0.0551 * * * \\
(0.0017)\end{array}$ & $\begin{array}{c}-173.7000^{* * *} \\
(6.8598)\end{array}$ & $\begin{array}{c}0.0455^{* * * *} \\
(0.0017)\end{array}$ & $\begin{array}{c}-204.4912^{* * * *} \\
(8.3666)\end{array}$ & $\begin{array}{c}0.0527 * * * \\
(0.0019)\end{array}$ \\
\hline Race Other & $\begin{array}{c}-67.4238 * * * \\
(14.2741)\end{array}$ & $\begin{array}{l}0.0027^{*} \\
(0.0016)\end{array}$ & $\begin{array}{c}-97.6485^{* * * *} \\
(15.0332)\end{array}$ & $\begin{array}{c}0.0099 * * * \\
(0.0016)\end{array}$ & $\begin{array}{c}-75.7623 * * * \\
(13.2895)\end{array}$ & $\begin{array}{c}0.0037 * * \\
(0.0015)\end{array}$ & $\begin{array}{c}-102.3112^{* * *} \\
(13.3970)\end{array}$ & $\begin{array}{c}0.0100 * * * \\
(0.0015)\end{array}$ \\
\hline Hispanic & $\begin{array}{c}18.5058 * * * \\
(6.6067)\end{array}$ & $\begin{array}{c}-0.0130 * * * \\
(0.0018)\end{array}$ & $\begin{array}{c}-30.1871 * * * \\
(4.7348)\end{array}$ & $\begin{array}{l}-0.0015 \\
(0.0013)\end{array}$ & $\begin{array}{c}23.1276 * * * \\
(4.5138)\end{array}$ & $\begin{array}{c}-0.0134^{* * * *} \\
(0.0016)\end{array}$ & $\begin{array}{c}-20.4416 * * * \\
(3.1577)\end{array}$ & $\begin{array}{c}-0.0032^{* * *} \\
(0.0010)\end{array}$ \\
\hline Married & $\begin{array}{c}82.9175 * * * \\
(4.6869)\end{array}$ & $\begin{array}{c}-0.0237 * * * \\
(0.0015)\end{array}$ & $\begin{array}{c}56.3731^{* * *} \\
(2.1565)\end{array}$ & $\begin{array}{c}-0.0174 * * * \\
(0.0009)\end{array}$ & $\begin{array}{c}81.8728^{* * *} \\
(4.3850)\end{array}$ & $\begin{array}{c}-0.0232 * * * \\
(0.0014)\end{array}$ & $\begin{array}{c}55.8356 * * * \\
(2.0231)\end{array}$ & $\begin{array}{c}-0.0170 * * * \\
(0.0009)\end{array}$ \\
\hline Cigarette Tax & $\begin{array}{l}3.9495 * \\
(2.1934)\end{array}$ & $\begin{array}{c}-0.0011^{* *} \\
(0.0005)\end{array}$ & $\begin{array}{c}3.6833 \\
(2.4422)\end{array}$ & $\begin{array}{l}-0.0010^{*} \\
(0.0005)\end{array}$ & $\begin{array}{c}4.7928 * * \\
(1.9495)\end{array}$ & $\begin{array}{c}-0.0013^{* *} \\
(0.0005)\end{array}$ & $\begin{array}{c}3.9983 * * \\
(1.9858)\end{array}$ & $\begin{array}{c}-0.0011^{* *} \\
(0.0005)\end{array}$ \\
\hline $\begin{array}{l}\text { Maternal Smoking } \\
\text { Year Fixed Effects } \\
\text { Fixed Effects }\end{array}$ & $\begin{array}{l}\text { No } \\
\text { Yes } \\
\text { State } \\
\end{array}$ & $\begin{array}{l}\text { No } \\
\text { Yes } \\
\text { State }\end{array}$ & $\begin{array}{l}\text { Yes } \\
\text { Yes } \\
\text { State }\end{array}$ & $\begin{array}{l}\text { Yes } \\
\text { Yes } \\
\text { State }\end{array}$ & $\begin{array}{c}\text { No } \\
\text { Yes } \\
\text { County }\end{array}$ & $\begin{array}{c}\text { No } \\
\text { Yes } \\
\text { County }\end{array}$ & $\begin{array}{c}\text { Yes } \\
\text { Yes } \\
\text { County }\end{array}$ & $\begin{array}{c}\text { Yes } \\
\text { Yes } \\
\text { County }\end{array}$ \\
\hline Observations & $23,123,958$ & $23,123,958$ & $23,123,958$ & $23,123,958$ & $23,123,958$ & 23,123,958 & $23,123,958$ & $23,123,958$ \\
\hline
\end{tabular}

Notes: Coefficients from OLS models are reported. Standard errors are clustered at the state level and reported in parentheses.

Asterisks denote statistical significance as follows: *** p-value $\leq 0.01 ; * * 0.01<\mathrm{p}$-value $\leq 0.05 ; * 0.05<\mathrm{p}$-value $\leq 0.10$. 


\section{Appendix Table 6}

Effects of Comprehensive Smoking Bans in All Venues (Workplace, Restaurants, and Bars) on Infant Health Mothers' Education Level: High school graduate or less

Results Using 1995-2009 Sample of Births

(Gao and Baughman 2017)

Reference Group: No Bans in any Venue

\begin{tabular}{|c|c|c|c|c|c|c|c|c|}
\hline Reference Group: All other & $\begin{array}{c}\text { (1) } \\
\text { Birthweight }\end{array}$ & $\begin{array}{c}\text { (2) } \\
\text { Low } \\
\text { Birthweight }\end{array}$ & $\begin{array}{c}\text { (3) } \\
\text { Birthweight }\end{array}$ & $\begin{array}{c}\text { (4) } \\
\text { Low } \\
\text { Birthweight }\end{array}$ & $\begin{array}{c}\text { (5) } \\
\text { Birthweight }\end{array}$ & $\begin{array}{c}\text { (6) } \\
\text { Low } \\
\text { Birthweight }\end{array}$ & $\begin{array}{c}\text { (7) } \\
\text { Birthweight }\end{array}$ & $\begin{array}{c}\text { (8) } \\
\text { Low } \\
\text { Birthweight }\end{array}$ \\
\hline Comprehensive Ban - All Venues & $\begin{array}{l}9.2221^{* *} \\
(3.5563)\end{array}$ & $\begin{array}{c}-0.0020^{* *} \\
(0.0008)\end{array}$ & $\begin{array}{l}7.8431^{*} \\
(4.0172)\end{array}$ & $\begin{array}{l}-0.0016^{*} \\
(0.0009)\end{array}$ & $\begin{array}{l}8.7424^{* *} \\
(3.6035)\end{array}$ & $\begin{array}{c}-0.0020^{* *} \\
(0.0008)\end{array}$ & $\begin{array}{l}6.6477^{*} \\
(3.7144)\end{array}$ & $\begin{array}{l}-0.0015^{*} \\
(0.0009)\end{array}$ \\
\hline Mother's Age & $\begin{array}{c}3.0172^{* * *} \\
(0.3790)\end{array}$ & $\begin{array}{c}0.0010^{* * *} \\
(0.0001)\end{array}$ & $\begin{array}{c}3.1787 * * * \\
(0.3463)\end{array}$ & $\begin{array}{c}0.0009 * * * \\
(0.0001)\end{array}$ & $\begin{array}{c}2.8435^{* * * *} \\
(0.3590)\end{array}$ & $\begin{array}{c}0.0010^{* * *} \\
(0.0001)\end{array}$ & $\begin{array}{c}3.1373^{* * *} \\
(0.3158)\end{array}$ & $\begin{array}{c}0.0010^{* * * *} \\
(0.0001)\end{array}$ \\
\hline Mother's Education & $\begin{array}{l}3.8021^{* *} \\
(1.7511)\end{array}$ & $\begin{array}{c}-0.0009^{* *} \\
(0.0003)\end{array}$ & $\begin{array}{c}1.4567 \\
(1.4464)\end{array}$ & $\begin{array}{c}-0.0003 \\
(0.0003)\end{array}$ & $\begin{array}{c}4.5590^{* * * *} \\
(1.4320)\end{array}$ & $\begin{array}{c}-0.0010^{* * *} \\
(0.0003)\end{array}$ & $\begin{array}{l}2.0512^{*} \\
(1.0782)\end{array}$ & $\begin{array}{c}-0.0005^{* *} \\
(0.0002)\end{array}$ \\
\hline Black & $\begin{array}{c}-175.3561^{* * *} \\
(6.0826)\end{array}$ & $\begin{array}{c}0.0465^{* * *} \\
(0.0017)\end{array}$ & $\begin{array}{c}-211.8615^{* * *} \\
(7.1751)\end{array}$ & $\begin{array}{c}0.0550^{* * *} \\
(0.0019)\end{array}$ & $\begin{array}{c}-173.7890^{* * *} \\
(7.3271)\end{array}$ & $\begin{array}{c}0.0456^{* * *} \\
(0.0018)\end{array}$ & $\begin{array}{c}-204.9080^{* * *} \\
(8.9944)\end{array}$ & $\begin{array}{c}0.0528^{* * *} \\
(0.0021)\end{array}$ \\
\hline Race Other & $\begin{array}{c}-73.7237^{* * *} \\
(13.4753)\end{array}$ & $\begin{array}{l}0.0036^{* *} \\
(0.0014)\end{array}$ & $\begin{array}{c}-104.8950^{* * *} \\
(14.0053)\end{array}$ & $\begin{array}{c}0.0109 * * * \\
(0.0013)\end{array}$ & $\begin{array}{c}-82.5045^{* * *} \\
(12.0550)\end{array}$ & $\begin{array}{c}0.0046^{* * *} \\
(0.0014)\end{array}$ & $\begin{array}{c}-109.8076^{* * *} \\
(11.7563)\end{array}$ & $\begin{array}{c}0.0110^{* * *} \\
(0.0012)\end{array}$ \\
\hline Hispanic & $\begin{array}{c}17.3087^{* *} \\
(6.6349)\end{array}$ & $\begin{array}{c}-0.0127^{* * *} \\
(0.0018)\end{array}$ & $\begin{array}{c}-31.6472^{* * *} \\
(4.6899)\end{array}$ & $\begin{array}{l}-0.0012 \\
(0.0012)\end{array}$ & $\begin{array}{c}22.0665^{* * *} \\
(4.2149)\end{array}$ & $\begin{array}{c}-0.0131^{* * *} \\
(0.0015)\end{array}$ & $\begin{array}{c}-21.6659^{* * *} \\
(2.9660)\end{array}$ & $\begin{array}{c}-0.0029^{* * *} \\
(0.0009)\end{array}$ \\
\hline Married & $\begin{array}{c}84.2092^{* * *} \\
(4.9000)\end{array}$ & $\begin{array}{c}-0.0240^{* * *} \\
(0.0015)\end{array}$ & $\begin{array}{c}57.1260^{* * *} \\
(2.1204)\end{array}$ & $\begin{array}{c}-0.0176^{* * *} \\
(0.0009)\end{array}$ & $\begin{array}{c}83.4083^{* * *} \\
(4.5458)\end{array}$ & $\begin{array}{c}-0.0235^{* * *} \\
(0.0015)\end{array}$ & $\begin{array}{c}56.8536^{* * *} \\
(1.9121)\end{array}$ & $\begin{array}{c}-0.0173^{* * *} \\
(0.0009)\end{array}$ \\
\hline Cigarette Tax & $\begin{array}{l}4.5853^{* *} \\
(2.1303)\end{array}$ & $\begin{array}{c}-0.0012^{* *} \\
(0.0005)\end{array}$ & $\begin{array}{l}4.4103^{*} \\
(2.3703)\end{array}$ & $\begin{array}{c}-0.0012^{* *} \\
(0.0005)\end{array}$ & $\begin{array}{l}4.8645^{* *} \\
(1.9898)\end{array}$ & $\begin{array}{c}-0.0014^{* *} \\
(0.0005)\end{array}$ & $\begin{array}{l}4.0603^{*} \\
(2.0290)\end{array}$ & $\begin{array}{c}-0.0012^{* *} \\
(0.0005)\end{array}$ \\
\hline $\begin{array}{l}\text { Maternal Smoking } \\
\text { Year Fixed Effects } \\
\text { Fixed Effects }\end{array}$ & $\begin{array}{c}\text { No } \\
\text { Yes } \\
\text { State }\end{array}$ & $\begin{array}{l}\text { No } \\
\text { Yes } \\
\text { State } \\
\end{array}$ & $\begin{array}{l}\text { Yes } \\
\text { Yes } \\
\text { State } \\
\end{array}$ & $\begin{array}{l}\text { Yes } \\
\text { Yes } \\
\text { State }\end{array}$ & $\begin{array}{c}\text { No } \\
\text { Yes } \\
\text { County }\end{array}$ & $\begin{array}{c}\text { No } \\
\text { Yes } \\
\text { County }\end{array}$ & $\begin{array}{c}\text { Yes } \\
\text { Yes } \\
\text { County }\end{array}$ & $\begin{array}{c}\text { Yes } \\
\text { Yes } \\
\text { County }\end{array}$ \\
\hline Observations & 20863132 & 20863132 & 20863132 & 20863132 & 20863132 & 20863132 & 20863132 & 20863132 \\
\hline
\end{tabular}

Notes: Coefficients from OLS models are reported. Standard errors are clustered at the state level and reported in parentheses.

Asterisks denote statistical significance as follows: *** p-value $\leq 0.01 ; * * 0.01<\mathrm{p}$-value $\leq 0.05 ; * 0.05<\mathrm{p}$-value $\leq 0.10$. 